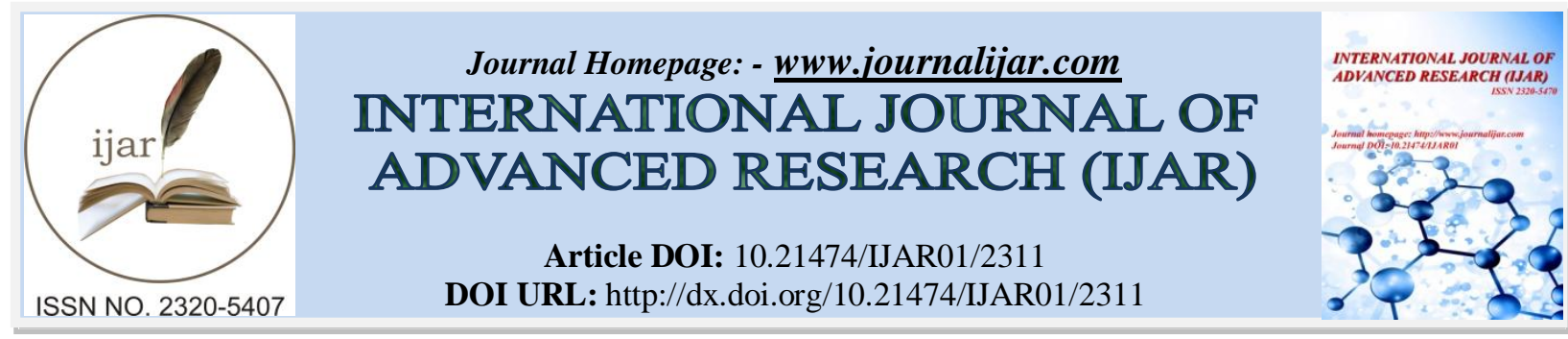

RESEARCH ARTICLE

\title{
IN VIVO ASSESSMENT OF ANTI-ARTHRITIC ACTIVITY OF WITHANIA COAGULANS DUNAL FRUITS.
}

"Archana K. Shendkar', Sugandha G. Chaudhari ${ }^{1}$ and Dr. Yogesh K. Shendkar ${ }^{2}$.

1. Department of Pharmacology, Dr.L.H.Hiranandani College of Pharmacy, Ulhasnagar, District-Thane, India.

2. Department of Medicine, Virar Homeopathic Medical College, Virar, District-Thane, India.

\section{Manuscript Info}

Manuscript History

Received: 29 September 2016

Final Accepted: 30 October 2016

Published: November 2016

Key words:-

Anti-arthritic, Withania Coagulans,

Complete Freund's adjuvant, arthritis index, dorsal flexion.

\begin{abstract}
The aim of this study was to determine in-vivo anti-arthritic activity of methanolic and hydro alcoholic extract of Withania Coagulans Dunal fruits i.e. Withania Coagulans Methanolic Extract (WCME) and Withania Coagulans Hydro alcoholic Extract (WCHAE). Phytochemical analysis has indicated presence of alkaloids, flavonoids, glycosides, steroids, saponins, fixed oil, carbohydrates. Both the extracts have showed anti-arthritic activity by Complete Freund's adjuvant induced arthritis (CFA) in rats method.Treatment with WCME-200mg $/ \mathrm{kg}$, WCME-500mg $/ \mathrm{kg}$, WCHAE- $450 \mathrm{mg} / \mathrm{kg}$ caused significant $(p<0.01)$ inhibition of the arthritis index score, paw edema volume, joint area and pain perception parameters like dorsal flexion and motility along with rise in stair climb score in comparison with disease control (CFA induced) groups on $28^{\text {th }}$ day. Both the extracts showed the good anti-inflammatory activity but WCHAE showed the most significant anti-arthritic activity than WCME. The findings of the present study suggested that Withania Coagulans dunal fruits could be a potential natural source of ant-arthritis activity which is very important against treatment of rheumatoid arthritis disease.
\end{abstract}

Copy Right, IJAR, 2016,. All rights reserved.

\section{Introduction:-}

RA is chronic inflammatory and autoimmune diseases affects millions of people across the world leading to suffering, economic loss and premature death. Common inflammatory diseases include asthma, chronic obstructive pulmonary diseases (COPD), allergic rhinitis, osteoarthritis, inflammatory bowel diseases (IBD) and psoriasis. Inflammatory diseases including different types of rheumatic diseases are a major cause of mortality of the working force throughout the world. This has been called the 'king of the human miseries.'

Inflammation is the reaction of living tissues to injury, infection or irritation of foreign substance. Lysosomal enzyme released during the inflammation leads to the tissue injury which is responsible for pathological condition of rheumatoid arthritis. Inflammation manifest in the form of painful swelling associated with some changes in skin covering at the site. It can be classified either acute or chronic. Acute inflammation is initial response of body to harmful stimuli and prolonged inflammation is known as chronic inflammation. ${ }^{[1]}$

The immune system is a well-organized and well-regulated system. The deregulation of the immune system may lead to the development of RA with destructive inflammatory polyarticular joint potentially resulting in progressive

Corresponding Author:- Archana K. Shendkar.

Address:- Department of Pharmacology, Dr.L.H.Hiranandani College of Pharmacy, Ulhasnagar, District2059 
destruction of articular and periarticular structure. ${ }^{[2]}$ Autoimmune diseases occur when the body looses the ability to discriminate self proteins from non-self proteins. This loss of tolerance ultimately results in the destruction of self tissues by the immune system. Typically, autoimmune diseases are characterized by the presence of auto-antibodies and auto reactive $\mathrm{T}$ lymphocytes acting against specific self proteins. Within joints, the autoimmune mediated course of RA is characterized by four stages: (I) inflammation of the synovial membrane and joint capsule, (II) formation of a pannus (granulation tissue) that first covers and then invades cartilage and bone, (III) fibrous invasion of the pannus, (IV) calcification of the fibrous tissue. ${ }^{[3]}$

The therapy for rheumatism includes medications with steroids, non-steroidal anti-inflammatory drugs (NSAIDS) used to suppress the symptoms and disease modifying anti-rheumatic drugs (DMARDS) and immunosuppressant drugs required to inhibit or halt the immune process. ${ }^{[4]}$ Unfortunately, although these drugs have shown to improve signs and symptoms alter the natural history of the disease and improve quality of life but there is still no cure. In addition, these available therapies are associated with potential risks of death/ irreversible organ damage. ${ }^{[5]}$ Owing to these shortcomings, there is need to have a more effective and safe therapeutic strategy to treat RA. By virtue of its safety and efficacy, plants still hold their own unique place. The Ayurvedic systems of treatment are being increasingly recognized as an alternate approach to arthritic treatment. In India Herbal medicine has a traditional name "Ayurvedic". Ayurveda is derived from two Sanskrit words, namely, "Ayus" and "Veda," meaning life and knowledge, respectively. Major formulations used in ayurveda are based on herbs. Hence, there is need of systematic approach to find out the herbs which possess anti-inflammatory, immunomodulatory and anti-arthritic potential.

Withania Coagulans dunal fruits family Solanacea have many medicinal and therapeutic benefits although many of them have yet to be proven by science. Hence, current research project was undertaken with an objective to validate the claims of the medicinal use of Withania Coagulans dunal fruits as an anti-inflammatory, immunomodulatory and anti-arthritic agent.

\section{Material And Methods:- Material:-}

Freund's Complete Adjuvant (Difco Lab. USA) as inducing agent, SGOT (Randox Laboratories Ltd) SGPT (Randox Laboratories Ltd) ALP (Transasia Bio-Medical Ltd) used as diagnostic kit, Indomethacin (Ipca) as used as standard drug.

Chemicals: Anesthetic ether (Molychem), Formic acid (Molychem).

Instruments: Centrifugation machine (Remi), Semi- Auto analyzer (Randox Laboratories Ltd), Mersap Digital Plethysmometer (IITC Life Sciences, USA), Micrometer Screw Gauge (Aerospace), Stair climb apparatus.

All the above chemicals and instruments were obtained from the local suppliers.

\section{Collection And Authentication of Plant Material:-}

The fruits of Withania Coagulans Dunal belong to the family Solanacea is distributed throughout India. For the present study fruits were collected in the month of August from local suppliers in Mumbai (Maharashtra). The dried fruits was identified, confirmed and authenticated by A. S. Upadhye, Scientist, Plant Drug Authentication Service, Botany group, Plant Sciences Division, Agharkar Research Institute, Pune for further work. The dried fruit material was then pulverized by a mechanical grinder. The resulting coarse powder was then used for extraction.

\section{Processing of the WC Fruits to Obtain an Extract:- \\ Preparation of Extract:-}

Dried fruits of Withania Coagulans Dunal were coarse powdered and packed into Soxhlet column and extracted with methanol for methanolic extract. ${ }^{[6]}$ Whereas the water: methanol (40:60) is used for preparation of hydro alcoholic extract. ${ }^{[7]}$ The extract was concentrated under reduced pressure to get dried powder. The dried extract was stored in airtight container in refrigerator below $10^{\circ} \mathrm{c}$. Whereas the hydro alcoholic extract is prepared by using water and methanol in ratio of 40:60. To convert into powder, distillation process have been followed to recover solvent and then dried.

\section{Analysis of Extract:-}

a) Preliminary Phytochemical Studies 
Phytochemical studies of methanolic extract and hydro alcoholic extract of fruits part of Withania Coagulans Dunal was done. It is subjected to the different chemical tests in ordered to identify the presence of various phytoconstituents. Dragendorff's test, Mayer's test, Wagner's test, Hager's test for alkaloids, Molish's test, Fehling's test for carbohydrates, Legal's Test for glycosides, Liebermann burchard's test for steroidal compounds, Lead acetate Test, Reaction with Sodium Hydroxide for flavonoids, Spot test for fixed oil, foam test for saponin glycosides was carried out for their presence. ${ }^{[8]}$

\section{b) TLC Profile}

TLC profile was developed for WCME and WCHAE.

\section{Procedure:-}

Thin layer chromatography of extract was performed on silica gel plates. A TLC plate of width $4 \mathrm{~cm}$ and height 9 $\mathrm{cm}$ was taken and origin was marked at $1.2 \mathrm{~cm}$ from one end of the plate. The solvent system chloroform: methanol in the ratio of 9:1 was prepared. $10 \mu \mathrm{l}$ of samples were spotted on the TLC plate, air dried and placed in chromatographic chamber previously saturated with the solvent system. The run was performed until the solvent reaches the top of the plate. Dried and sprayed the plate with $10 \%$ sulphuric acid and air dried. Spot were developed by heating in hot air oven. The spot developed were recorded and $R_{f}$ value was calculated. The $R_{f}$ value can be determined as follows:

$\mathrm{R}_{\mathrm{f}}=\frac{\text { Distance traveled by solute }}{\text { Distance traveled by the solvent }}$

\section{Methods:-}

\section{Animals:-}

Sprague Dawley rats of either sex weighing 150- 200 gm were used in the study. They were procured from Bharat Serum, Thane, India. The animals were acclimatized for ten days under laboratory conditions. They were housed in polypropylene cages and maintained at $22 \pm 1^{\circ} \mathrm{C}$, under a $12 \mathrm{~h} \mathrm{light/dark} \mathrm{cycle,} \mathrm{with} \mathrm{a} \mathrm{free} \mathrm{access} \mathrm{to} \mathrm{commercial} \mathrm{diet}$ and water ad libitum throughout the study. The care, use and experimental procedures conducted in accordance with guidelines and procedures for animal experimentation as prescribed by Committee for Purpose of Control and Supervision of Experiments on Animals (CPCSEA), India. Experimental protocol was approved by Institutional Animal Ethics Committee (IAEC).

\section{Determination of Acute Oral Toxicity Study (LD50):-}

The acute oral toxicity study of methanolic and hydro-alcoholic extract of Withania Coagulans Dunal fruits were determined in female Sprague Dawley rats in accordance with OECD (Organization for Economic Co-operation and Development) guideline 425 to evaluate safety profile of these plant extract.

\section{In Vivo Assessment of Anti-arthritic Activity Complete Freund's Adjuvant Induced Arthritis in Aats (CFA) ${ }^{[9,10]}$ Procedure}

Arthritis was induced by injecting a $0.1 \mathrm{ml}(0.1 \% \mathrm{w} / \mathrm{v})$ suspension of killed mycobacterium tuberculosis bacteria homogenized in liquid paraffin i.e. CFA into the right hind paw.

Animals were divided into 6 groups of 6 rats each.

Group I: The Disease Control group was administered with normal saline.

Group II: The Normal Control group was administered with normal saline

Group III: The standard group received Indomethacin $(10 \mathrm{mg} / \mathrm{kg})$ orally.

Group IV and Group V: The test group was administered with methanolic extract of WC

fruits at the dose of $200 \mathrm{mg} / \mathrm{kg}$ and $500 \mathrm{mg} / \mathrm{kg}$ rats orally.

Group VI: The test group was administered with hydro-alcoholic extract of WC fruits at the dose of $450 \mathrm{mg} / \mathrm{kg}$ rats orally

Drug treatment was started from the initial day from the day of adjuvant injection ( 0 day), 30 minutes before adjuvant injection and continued till 28th day. Paw edema and joint thickness (perimeter) was measured on 7 th, 14th, 21st and 28th day by using Mersap digital plethysmometer and micrometer screw gauze respectively. The mean changes in injected paw edema and joint thickness, were calculated on respective days. 


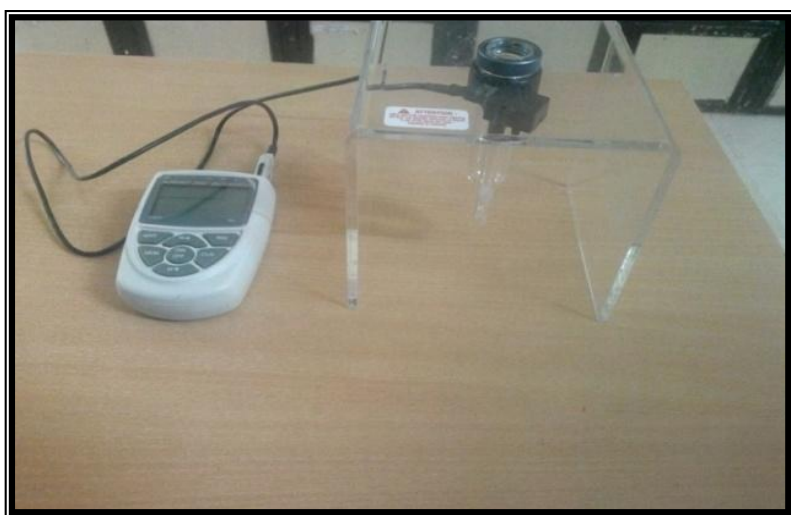

Figure-1:- Mersap Digital plethysmometer

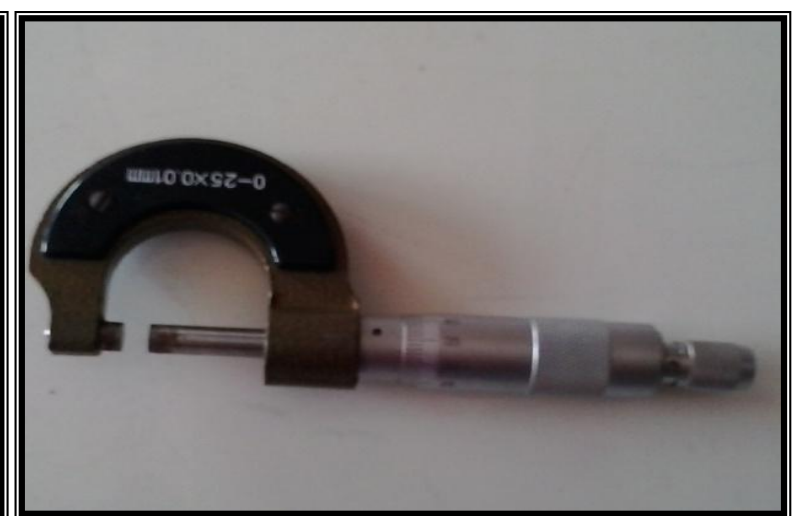

Figure-2:- Micrometer Screw Gauge

\section{Evaluation:-}

A) Assessment of Arthritic Parameters

\section{i) Arthritis Index}

Assessment of arthritis index was done by visual observation of level of inflammation found on left hind paw in terms of edema and redness. The scoring of arthritis index was done on day $7^{\text {th }}, 14^{\text {th }}, 21^{\text {st }}$, and on $28^{\text {th }}$ day. Scoring is given in following manner.

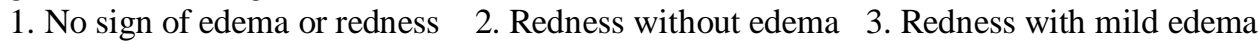

4. Redness with severe edema 5. Redness, severe edema and stiffness in movement

\section{ii) Paw Volume}

Paw edema was measured on $7^{\text {th }}, 14^{\text {th }}, 21^{\text {st }}$ and $28^{\text {th }}$ day by using Mersap digital plethysmometer. The mean changes in injected paw edema were calculated on respective days.

\section{iii) Joint Thickness}

Joint thickness (perimeter) was measured on $7^{\text {th }}, 14^{\text {th }}, 21^{\text {st }}$ and $28^{\text {th }}$ day by using micrometer screw gauge. The mean changes in joint thickness, were calculated on respective days.

\section{B) Assessment of Pain Perception Parameter}

\section{i) Arthritic Dorsal Flexion Pain Test}

Ankle joint was gently flexed dorsally until the toes touched the front of the leg for 5 times with an inter-test interval of 5 seconds. Pain was scored zero when the animal showed neither squeaking nor quick leg-withdrawal. The scores was 1 when either reaction appeared, and scored 2 when both reactions appeared. All the groups were evaluated in this manner on $7^{\text {th }}, 14^{\text {th }}, 21^{\text {st }}$ and on $28^{\text {th }}$ day.

\section{ii) Stair Climbing Activity}

Overnight fasting animals were trained for one week to climb a staircase with steps at 5,10 and $15 \mathrm{~cm}$ having water at second step and food at the third step. Climbing ability of the rats in the above groups scored 0 , if the rats did not climb ; 1 , if the rats climbed onto step- $1 ; 2$, if the rats climbed onto step -2 and 3 , if the rats could climb all the three steps. All the groups were evaluated in this manner on $7^{\text {th }}, 14^{\text {th }}, 21^{\text {st }}$, and on $28^{\text {th }}$ day.

\section{iii) Motility Test}

The motility patterns of rats was observed for a period of 5 minutes on plane surface and score 0 , if the rat walked easily, score 1, if rat walked with more difficulty and scored 2, if rat walked with more difficulty and avoided touching the toes of the inflamed paw to the floor. All the groups were evaluated in this manner on $7^{\text {th }}, 14^{\text {th }}, 21^{\text {st }}$, and on day $28^{\text {th }}$. ${ }^{[11,12]}$

\section{C) Hematological Determination in Arthritic Rats}

On $28^{\text {th }}$ day blood was withdrawn through retro-orbital vein puncture of all groups by anaesthetizing the animals with diethyl ether and the biochemical parameters like Hemoglobin (HB) content, total White blood cells (WBC) count, Hematocrit value (HCT), Red blood cells (RBC), Erythrocyte sedimentation rate (ESR), Platelet (PLT), Neutrophil (NEU), Lymphocytes (LYM) were analyzed. ${ }^{[9,13,14]}$ 


\section{D) Histopathological Analysis of Arthritic Rats}

On $28^{\text {th }}$ day all animals were sacrificed and their hind limbs were removed surgically and fixed in $10 \%$ buffered formalin. Then limbs were decalcified in $15 \%$ formic acid for histopathological study. ${ }^{[15]}$

\section{E) Radiological Analysis of Arthritic Rats}

Before sacrificing the animals, X- rays were taken on $14^{\text {th }}$ and $28^{\text {th }}$ day at the joint of hind paw of the animals for evaluating the bone and cartilage damage. Radiographs were taken using X- ray apparatus (Siemen- 60 MA, Germany) and industrial X-Ray film (Fuji photo film, Japan). The X-ray apparatus was operated at $220 \mathrm{~V}$ with a 40 $\mathrm{V}$ peak, 0.2 second exposure time, and a $60 \mathrm{~cm}$ tube to film distance for anterior-posterior projection. ${ }^{[15]}$

\section{F) Analysis of Serum Transaminases}

The blood was collected after sacrificing the animals of all groups on $28^{\text {th }}$ day. It is then centrifuged (REMI) and serum was then analyzed for lysosomal enzymes such as serum glutamate pyruvate transaminase (SGPT), serum glutamate oxaloacetate transaminase (SGOT) and alkaline phosphatase (ALP) by using SGPT, SGOT and ALP analysis kit. ${ }^{[16]}$

\section{Principle activity of AST present in the serum sample. \\ Reactions \\ 2-oxoglutarate + L-Aspartate \\ Oxaloacetate + NADH \\ Sample + NADH

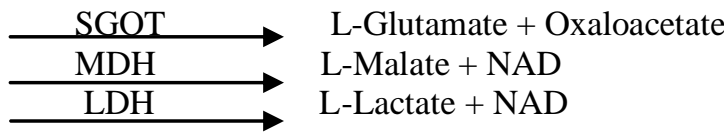 \\ Procedure}

i) Estimation of Serum Glutamate Oxaloacetate Transaminase Activity (SGOT/AST) [U.V. Kinetic method]

Serum Glutamate Oxaloacetate Transaminase (SGOT or AST) catalyzes the reversible transfer of an amino group from L-aspartate to 2-Oxoglutarate forming L-Glutamate and oxaloacetate. The rate of this reaction is monitored by an indicator reaction coupled with malate dehydrogenase (MDH). The oxaloacetate produced is reduced to malate ion by MDH in the presence of NADH (Nicotinamide adenine Dinucleotide). The oxidation of NADH in this reaction is measured as a decrease in the absorbance of NADH at $340 \mathrm{~nm}$, which is proportional to SGOT activity. The rate of decrease in concentration of NADH measured spectrophotometrically is proportional to the catalytic

Table 1:- Preparation of Blank, STD and Sample for SGOT Test

\begin{tabular}{|c|c|}
\hline Pipette & Sample $(\boldsymbol{\mu l})$ \\
\hline Working reagent & 500 \\
Sample & 50 \\
\hline
\end{tabular}

As mentioned in the above table blank, standard and sample was prepared by considering $500 \mu \mathrm{l}$ of working reagent and $50 \mu \mathrm{l}$ each of distilled water, standard and sample respectively, later all the samples were aspirated individually and absorbance was recorded at $340 \mathrm{~nm}$.

\section{ii) Estimation of Serum Glutamate Pyruvate Transaminase Activity (SGPT/ALT) [U.V. Kinetic Method] Principle}

Serum Glutamate Pyruvate Transaminase (SGPT or ALT) catalyses the reversible transfer of amino group from Lalanine to 2-oglutarate forming pyruvate and L-glutamate. The pyruvate produced is reduced to L-Lactate by lactate dehydrogenase (LDH) and NADH. The oxidation of NADH in this reaction is measured as a decreased in the absorbance of NADH at $340 \mathrm{~nm}$ which is proportional to the SGPT activity. The rate of decrease in concentration of NADH measured by UV kinetic method is proportional to catalytic activity of ALT present in the serum sample.

\section{Reactions}

$\alpha$-ketoglutarate + L-Alanine Pyruvate $+\mathrm{NADH}+\mathrm{H}^{+}$

\begin{tabular}{|c|c|}
\hline SGPT & te + Pyruvate \\
\hline LDH & L-Lactate $+\mathrm{NAD}^{+}$ \\
\hline
\end{tabular}


Procedure

Table 2:- Preparation of Blank, STD and Sample for SGPT test

\begin{tabular}{|c|c|}
\hline Pipette & Sample $(\boldsymbol{\mu l})$ \\
\hline Working reagent & 500 \\
Sample & 50 \\
\hline
\end{tabular}

As mentioned in the above SGOT, the same procedure had been followed.

iii) Estimation of Alkaline Phosphatase Activity (ALP)

Principle

Phosphatase is catalyses the hydrolysis of phosphates. Alkaline and acid phosphatases are differentiated by $\mathrm{pH}$ range of their optimum activities. The serum alkaline phosphatase hydrolyses p-nitro phenyl phosphate in the presence of oxidizing agent $\mathrm{Mg}^{+2}$

In the phosphatase determination, p-nitrophenylphosphate is used as substrate, which is dissociated by the enzyme into p-nitrophenolate and phosphate. The phenolate liberation occurs as yellow anion, which is then determined by using UV method. The amount of p-nitrophenolate liberated in unit time is directly proportional to the phosphatase activity.

\section{Reaction}

p-Nitrophenyl phosphate $\quad$ ALP, $\mathrm{Mg}^{+2} \longrightarrow \quad$ p-Nitrophenol + Phosphate

Procedure

Table 3:- Preparation of Blank, STD and Sample for ALP

\begin{tabular}{|c|c|}
\hline Pipette & Sample $(\boldsymbol{\mu l})$ \\
\hline Working reagent & 500 \\
Sample & 10 \\
\hline
\end{tabular}

As mentioned in the above blank, standard sample was prepared by considering $500 \mu$ of working reagent and $10 \mu l$ of each of distilled water, standard and sample respectively, later all the samples were aspirated individually and absorbance was recorded at $405 \mathrm{~nm}$.

\section{Statistical Data Analysis}

Data obtained were subjected to one way analysis of variance (ANOVA) followed by Dunnet's test *p $<0.05$, **p $<0.01$ was considered significant

\section{Results:-}

\subsection{Preliminary Phytochemical Evaluation}

Phytochemical studies of methanolic extract and hydro alcoholic extract of fruits part of Withania Coagulans Dunal showed the presence of carbohydrates, saponin glycosides, flavonoids, alkaloids, glycosides, steroidal compounds, fixed oils.

\section{TLC Profile}

$\mathrm{R}_{\mathrm{f}}$ value found to be 0.6 for WCME and 0.65 for WCHAE which is similar to that of $\mathrm{R}_{\mathrm{f}}$ value of Withaferin $A$ (i.e.0.6-0.65) hence it shows the presences of Withaferin $\mathrm{A}$ in the extracts.

\subsection{Acute Toxicity Studies}

WCME and WCHAE did not show any toxic or deleterious effects up to $2000 \mathrm{mg} / \mathrm{kg}$ oral dose. As the rats were administered up to maximal possible dose, the $\mathrm{LD}_{50}$ value of WCME and WCHAE could not be determined.

\section{a) Effect of WCE on Arthritis Index Score in FCA Induced Arthritis}

Effect of WCE on arthritis index was summarized in Table 4. Significant increased in arthritis index was observed in FCA treated group of animal when compared with normal animals. FCA increased arthritis index were significantly $(\mathrm{p}<0.05, \mathrm{p}<0.01, \mathrm{p}<0.01$ and $\mathrm{p}<0.01)$ reduced by treatment with WCME-200, WCME-500, WCHAE-450 and 
indomethacin $(10 \mathrm{mg} / \mathrm{kg})$ on $28^{\text {th }}$ day in comparison with disease control group in FCA induced arthritis model respectively.

Figure 3:- Effect of WCE on Arthritis Index Score

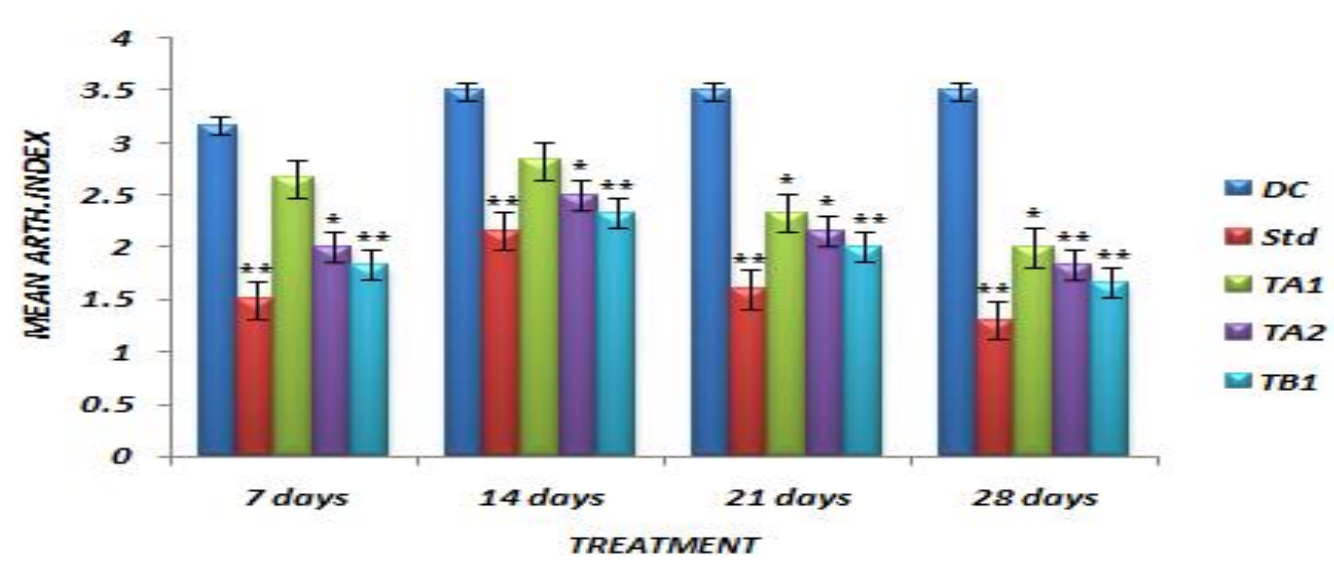

Values are expressed in mean \pm SEM $(\mathrm{n}=6),{ }^{*} \mathrm{p}<0.05,{ }^{*} \mathrm{p}<0.01$ vs Disease Control group, Data analyzed by One way ANOVA test followed by Dunnet's multiple test for comparison. Treatment of various groups is as follows, N: Normal, DC: Disease Control, STD: Standard, TA1: WCME- 200 mg/kg, TA2: WCME-500 mg/kg, TB1: WCHAE$450 \mathrm{mg} / \mathrm{kg}$

\section{b) Effect of WCE on Paw Edema in FCA Induced Arthritis}

Effect of WCE on paw edema was summarized in Table 4. In present study it was observed that treatment of WCME-500 and WCHAE-450 significantly $(\mathrm{p}<0.01)$ reduce the paw edema volume $(\mathrm{ml})$ on $28^{\text {th }}$ day in comparison with disease control group in FCA induced arthritis model. Here, in agreement with other studies, WCME and WCHAE effectively inhibited the development of edema, a characteristic sign of inflammation, in arthritic hind of arthritic rats.

Table 4:- Effect of WCE (200 mg/kg, 500mg/kg and $450 \mathrm{mg} / \mathrm{kg}$ ) on Arthritis parameters i.e. Arthritis Index and Paw Edema

\begin{tabular}{|c|c|c|c|c|c|c|c|c|}
\hline \multirow{3}{*}{$\begin{array}{c}\text { Experimental } \\
\text { Group } \\
\text { Days } \longrightarrow\end{array}$} & \multicolumn{8}{|c|}{ ARTHRITIC PARAMETERS } \\
\hline & \multicolumn{4}{|c|}{ ARTHRITIS INDEX } & \multicolumn{4}{|c|}{ PAW EDEMA } \\
\hline & Day 7 & Day 14 & Day 21 & Day 28 & Day 7 & Day 14 & Day 21 & Day 28 \\
\hline DC & $\begin{array}{l}3.17 \pm \\
0.167\end{array}$ & $\begin{array}{l}3.5 \pm \\
0.224\end{array}$ & $\begin{array}{l}3.5 \pm \\
0.224\end{array}$ & $\begin{array}{l}3.5 \pm \\
0.224\end{array}$ & $\begin{array}{l}1.95 \pm \\
0.101\end{array}$ & $\begin{array}{l}1.22 \pm \\
0.054\end{array}$ & $\begin{array}{l}1.36 \pm \\
0.039\end{array}$ & $\begin{array}{l}1.42 \pm \\
0.049\end{array}$ \\
\hline $\mathbf{N}$ & 0 & 0 & 0 & 0 & $\begin{array}{l}1.15 \pm \\
0.044 * *\end{array}$ & $\begin{array}{l}2.14 \pm \\
0.152 * *\end{array}$ & $\begin{array}{l}2.17 \pm \\
0.15^{* *}\end{array}$ & $\begin{array}{l}2.19 \pm \\
0.108^{* *}\end{array}$ \\
\hline STD & $\begin{array}{l}1.5 \pm \\
0.342 * *\end{array}$ & $\begin{array}{l}2.17 \pm \\
0.307 * *\end{array}$ & $\begin{array}{l}1.67 \pm \\
0.211 * *\end{array}$ & $\begin{array}{l}1.33 \pm \\
0.333 * *\end{array}$ & $\begin{array}{l}1.32 \pm \\
0.129 * *\end{array}$ & $\begin{array}{l}1.47 \pm \\
0.116 * *\end{array}$ & $\begin{array}{l}1.40 \pm \\
0.17 * *\end{array}$ & $\begin{array}{l}1.36 \pm \\
0.171 * *\end{array}$ \\
\hline TA1 & $\begin{array}{l}2.67 \pm \\
0.211\end{array}$ & $\begin{array}{l}2.83 \pm \\
0.167\end{array}$ & $\begin{array}{l}2.33 \pm \\
0.211 *\end{array}$ & $\begin{array}{l}2 \pm \\
0.258^{*}\end{array}$ & $\begin{array}{l}1.58 \pm \\
0.141\end{array}$ & $\begin{array}{l}1.73 \pm \\
0.193\end{array}$ & $\begin{array}{l}1.74 \pm \\
0.159\end{array}$ & $\begin{array}{l}1.68 \pm \\
0.164\end{array}$ \\
\hline TA2 & $\begin{array}{l}2 \pm \\
0.258 *\end{array}$ & $\begin{array}{l}2.5 \pm \\
0.224 *\end{array}$ & $\begin{array}{l}2.17 \pm \\
0.167 *\end{array}$ & $\begin{array}{l}1.83 \pm \\
0.447 * *\end{array}$ & $\begin{array}{l}1.50 \pm \\
0.134\end{array}$ & $\begin{array}{l}1.63 \pm \\
0.069 *\end{array}$ & $\begin{array}{l}1.62 \pm \\
0.044 *\end{array}$ & $\begin{array}{l}1.57 \pm \\
0.050 * *\end{array}$ \\
\hline TB1 & $\begin{array}{l}1.83 \pm \\
0.307 * *\end{array}$ & $\begin{array}{l}2.33 \pm \\
0.211^{* *}\end{array}$ & $\begin{array}{l}2 \pm \\
0.516^{* *}\end{array}$ & $\begin{array}{l}1.67 \pm \\
0.333 * *\end{array}$ & $\begin{array}{l}1.36 \pm \\
0.181^{*}\end{array}$ & $\begin{array}{l}1.58 \pm \\
0.144^{*}\end{array}$ & $\begin{array}{l}1.55 \pm \\
0.13^{* *}\end{array}$ & $\begin{array}{l}1.53 \pm \\
0.156^{* *}\end{array}$ \\
\hline
\end{tabular}

Values are expressed in Mean \pm SEM $(\mathrm{n}=6),{ }^{*} \mathrm{p}<0.05,{ }^{* *} \mathrm{p}<0.01$ vs Disease Control group, Data analyzed by One way ANOVA test followed by Dunnet's multiple test for comparison. Treatment of various groups is as follows, N: Normal, DC: Disease Control, STD: Standard, TA1: WCME- $200 \mathrm{mg} / \mathrm{kg}$, TA2: WCME-500 mg/kg, TB1: WCHAE$450 \mathrm{mg} / \mathrm{kg}$ 
Figure 4:- Photos of Paw Edema Showing Effect of WCE

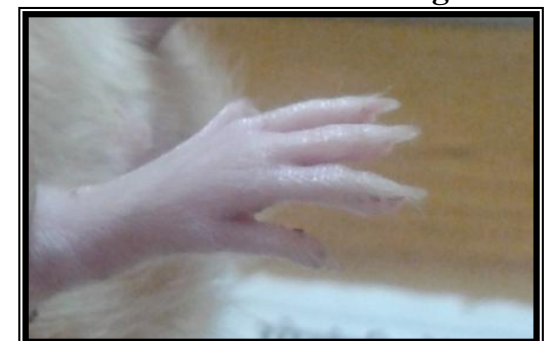

Normal

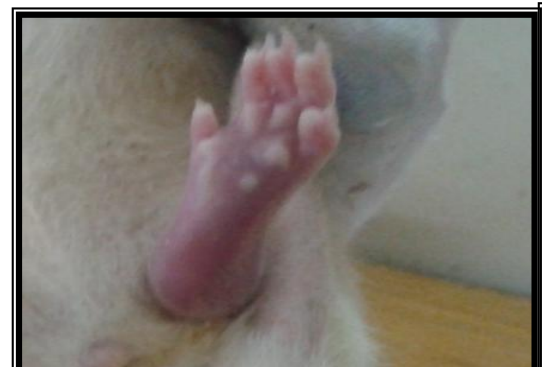

TA1

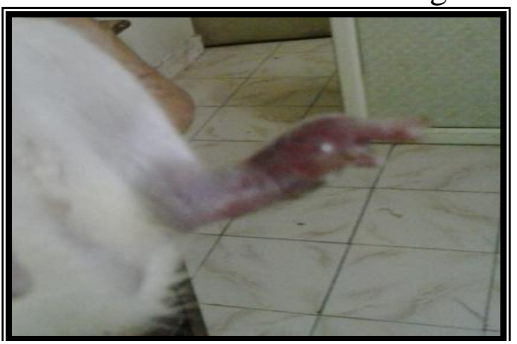

DC

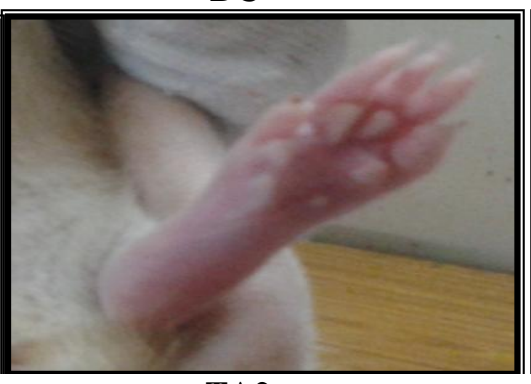

TA2

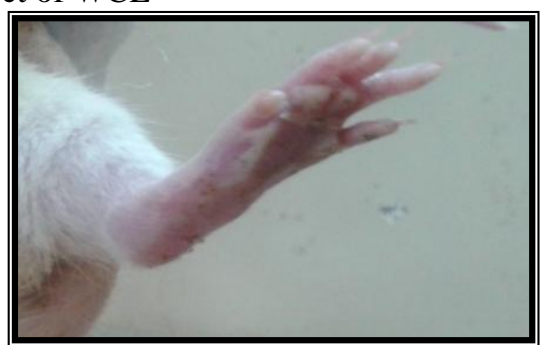

STD

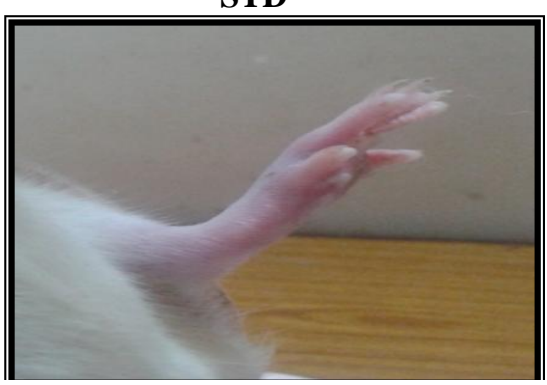

TB1

Figure 5:- Effect of WCE on Paw Edema

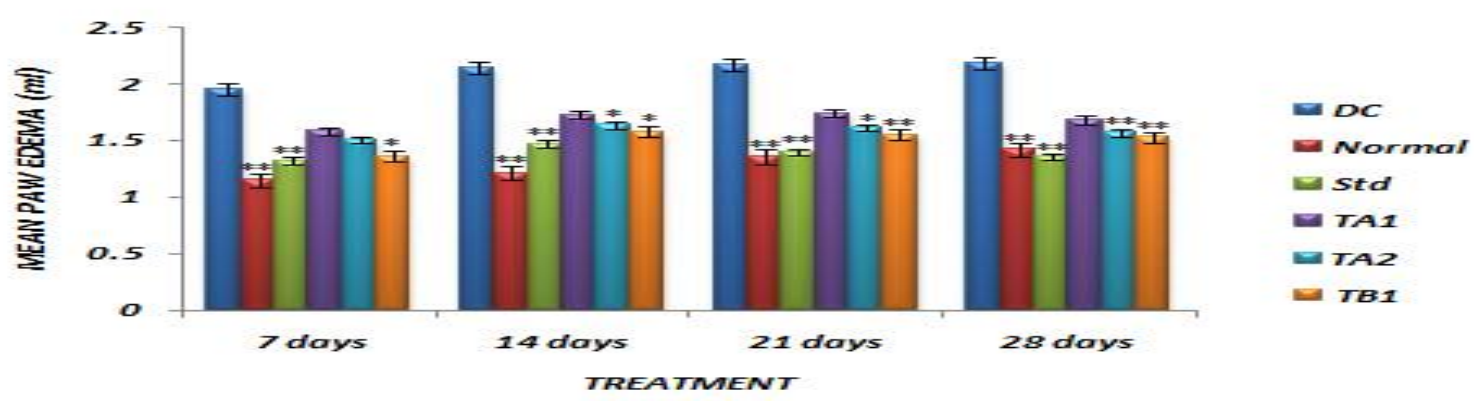

Values are expressed in mean \pm SEM $(n=6),{ }^{*} p<0.05$, ** $p<0.01$ vs Disease Control group, Data analyzed by One way ANOVA test followed by Dunnet's multiple test for comparison. Treatment of various groups is as follows, N: Normal, DC: Disease Control, STD: Standard, TA1: WCME- 200 mg/kg, TA2: WCME-500 mg/kg, TB1: WCHAE$450 \mathrm{mg} / \mathrm{kg}$

c) Effect of WCE on Joint Diameter (thickness) in FCA Induced Arthritis

In present study it was observed that treatment of WCME-500 and WCHAE-450 significantly ( $<<0.05$ and $p<0.01)$ reduce the paw edema volume $(\mathrm{ml})$ on $28^{\text {th }}$ day respectively in comparison with disease control group in FCA induced arthritis model.

Table 5:- Effect of WCE $(200 \mathrm{mg} / \mathrm{kg}, 500 \mathrm{mg} / \mathrm{kg}$ and $450 \mathrm{mg} / \mathrm{kg})$ on Joint Thickness

\begin{tabular}{|c|l|l|l|l|}
\hline Experimental Group & \multicolumn{4}{|c|}{ JOINT THICKNESS } \\
\hline Days & \multicolumn{1}{|c|}{$\mathbf{7}^{\text {th }}$} & \multicolumn{1}{|c|}{$\mathbf{1 4}^{\text {th }}$} & \multicolumn{1}{|c|}{$\mathbf{2 8}^{\text {th }}$} \\
\hline DC & $8.885 \pm 0.2067$ & $9.173 \pm 0.2154$ & $9.142 \pm 0.2532$ & $9.103 \pm 0.2785$ \\
\hline N & $7.263 \pm 0.3200^{* *}$ & $7.458 \pm 0.2666^{* *}$ & $7.685 \pm 0.2680^{* *}$ & $7.538 \pm 0.3279^{* *}$ \\
\hline STD & $7.453 \pm 0.1810^{* *}$ & $7.812 \pm 0.2381^{* *}$ & $7.74 \pm 0.2398^{* *}$ & $7.57 \pm 0.2930^{* *}$ \\
\hline TA1 & $8.353 \pm 0.3199$ & $8.542 \pm 0.3290$ & $8.555 \pm 0.2104$ & $8.398 \pm 0.2464$ \\
\hline TA2 & $7.888 \pm 0.2012^{*}$ & $8.367 \pm 0.2532$ & $8.253 \pm 0.2393^{*}$ & $8.14 \pm 0.2267^{*}$ \\
\hline TB1 & $7.838 \pm 0.2527^{*}$ & $8.018 \pm 0.2213^{*}$ & $7.988 \pm 0.1935^{* *}$ & $7.785 \pm 0.1016^{* *}$ \\
\hline
\end{tabular}

Values are expressed in Mean \pm SEM $(\mathrm{n}=6), * \mathrm{p}<0.05, * * \mathrm{p}<0.01$ vs Disease Control group, Data analyzed by One way ANOVA test followed by Dunnet's multiple test for comparison of various groups is as follows, N: Normal, DC: Disease Control, STD: Standard, TA1: WCME-. Treatment 200 mg/kg, TA2: WCME- 500 mg/kg, TB1: WCHAE-450 $\mathrm{mg} / \mathrm{kg}$ 
Figure 6:- Effect of WCE on Joint Diameter (thickness)

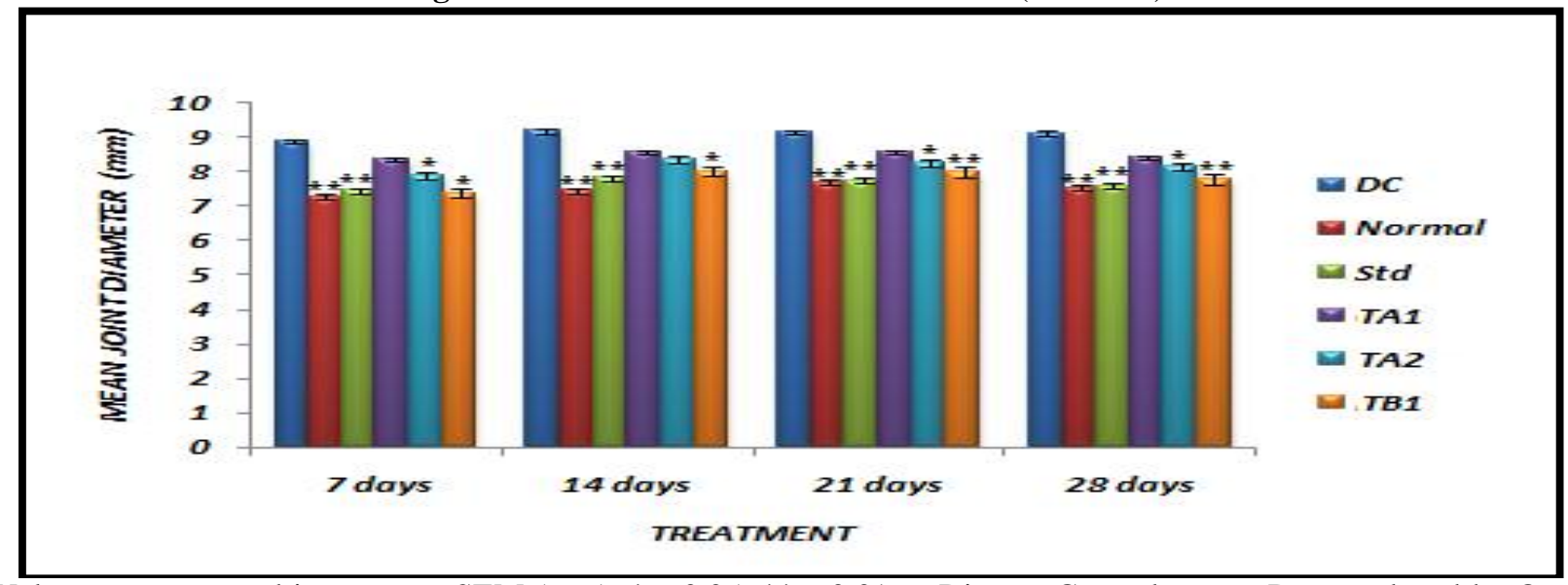

Values are expressed in mean \pm SEM $(n=6), * p<0.05$, **p<0.01 vs Disease Control group, Data analyzed by One way ANOVA test followed by Dunnet's multiple test for comparison. Treatment of various groups is as follows, N: Normal, DC: Disease Control, STD: Standard, TA1: WCME- 200 mg/kg, TA2: WCME-500 mg/kg, TB1: WCHAE$450 \mathrm{mg} / \mathrm{kg}$

\section{d) Effect of WCE on Dorsal Flexion Score in FCA Induced Arthritis}

In present study it has been observed that FCA induced increased dorsal flexion score were significantly $(\mathrm{p}<0.05$, $\mathrm{p}<0.01, \mathrm{p}<0.01$ and $\mathrm{p}<0.01)$ reduced by treatment with WCME-200, WCME-500, WCHAE-450 and indomethacin $(10 \mathrm{mg} / \mathrm{kg})$ on $28^{\text {th }}$ day in comparison with disease control group in FCA induced arthritis model respectively. As reduction in response given by arthritic animals on dorsal flexion was observed, hence it may be concluded that the level of inflammation is decreased with the progression of WCE treatment.

Figure 7:- Effect of WCE on Dorsal Flexion Score

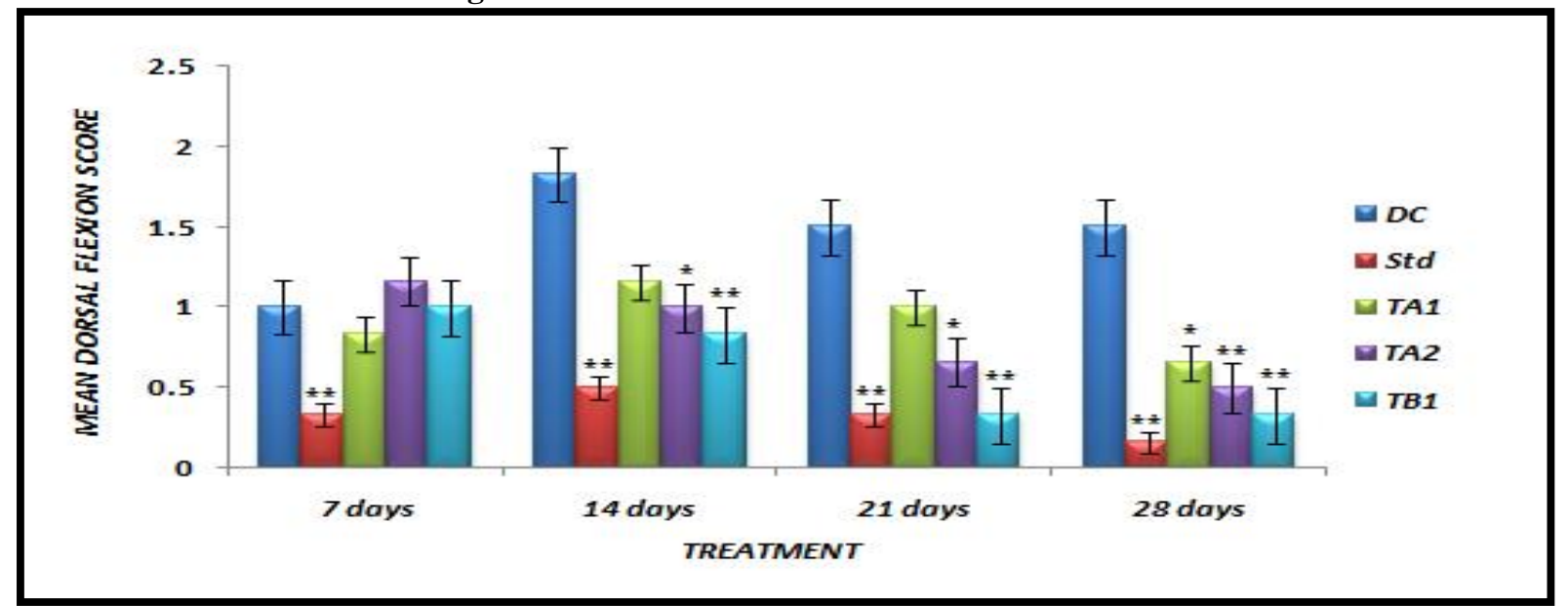

Values are expressed in mean \pm SEM $(\mathrm{n}=6),{ }^{*} \mathrm{p}<0.05$, ** $\mathrm{p}<0.01$ vs Disease Control group, Data analyzed by One way ANOVA test followed by Dunnet's multiple test for comparison. Treatment of various groups is as follows, DC: Disease Control, STD: Standard, TA1: WCME- $200 \mathrm{mg} / \mathrm{kg}$, TA2: WCME-500 mg/kg, TB1: WCHAE-450 $\mathrm{mg} / \mathrm{kg}$

\section{e) Effect of WCE on Motility Score in FCA Induced Arthritis}

In present study it has been observed that FCA induced increased motility score were significantly $(\mathrm{p}<0.05, \mathrm{p}<0.01$, $\mathrm{p}<0.01$ and $\mathrm{p}<0.01)$ reduced by treatment with WCME-200, WCME-500, WCHAE-450 and indomethacin (10 $\mathrm{mg} / \mathrm{kg}$ ) on $28^{\text {th }}$ day in comparison with disease control group in FCA induced arthritis model respectively. It has been observed in radiological study that ankle joint space of arthritic animals is retained effectively by continuous WCE treatment which may be responsible for enhanced motility behavior of arthritic animals which may lead to less 
stiffness in joints. Hence it can be proposed that level of motility increases with progression of WCE treatment in FCA induced arthritis.

Table 6:- Effect of WCE (200 mg/kg, 500mg/kg and $450 \mathrm{mg} / \mathrm{kg}$ ) on Pain Perception Parameters

\begin{tabular}{|c|c|c|c|c|c|c|c|c|c|c|c|}
\hline \multirow{3}{*}{$\begin{array}{l}\text { Exp. } \\
\text { Grp } \\
\text { Day }\end{array}$} & \multicolumn{11}{|c|}{ PAIN PERCEPTION PARAMETER } \\
\hline & \multicolumn{4}{|c|}{ DORSAL FLEXION SCORE } & \multicolumn{4}{|c|}{ MOTILITY SCORE } & \multicolumn{3}{|c|}{ STAIR CLIMB SCORE } \\
\hline & $7^{\text {th }}$ & $14^{\text {th }}$ & $21^{\mathrm{st}}$ & $28^{\text {th }}$ & $7^{\text {th }}$ & $14^{\text {th }}$ & $21^{\text {st }}$ & $28^{\text {th }}$ & $14^{\text {th }}$ & $21^{\text {st }}$ & $28^{\text {th }}$ \\
\hline DC & $\begin{array}{l}1.16 \pm \\
0.167\end{array}$ & $\begin{array}{l}1.833 \pm \\
0.167\end{array}$ & $\begin{array}{l}1.50 \pm \\
0.224\end{array}$ & $\begin{array}{l}1.50 \pm \\
0.224\end{array}$ & $\begin{array}{l}1.33 \pm \\
0.211\end{array}$ & $\begin{array}{l}1.667 \pm \\
0.211\end{array}$ & $\begin{array}{l}1.50 \pm \\
0.224\end{array}$ & $\begin{array}{l}1.50 \pm \\
0.224\end{array}$ & $\begin{array}{l}0.833 \pm \\
0.167\end{array}$ & $\begin{array}{l}0.667 \pm \\
0.307\end{array}$ & $\begin{array}{l}1.00 \pm \\
0.365\end{array}$ \\
\hline STD & $\begin{array}{l}0.33 \pm \\
0.21^{*}\end{array}$ & $\begin{array}{l}0.50 \pm \\
0.22 * *\end{array}$ & $\begin{array}{l}0.333 \pm \\
0.21 * *\end{array}$ & $\begin{array}{l}0.167 \pm \\
0.17 * *\end{array}$ & $\begin{array}{l}0.167 \pm \\
0.17^{* *}\end{array}$ & $\begin{array}{l}0.167 \pm \\
0.17 * *\end{array}$ & $\begin{array}{l}0.333 \pm \\
0.21 * *\end{array}$ & $\begin{array}{l}0.167 \pm \\
0.17 * *\end{array}$ & $\begin{array}{l}2.333 \pm \\
0.21 * *\end{array}$ & $\begin{array}{l}2.667 \pm \\
0.21 * *\end{array}$ & $\begin{array}{l}2.667 \pm \\
0.21 * *\end{array}$ \\
\hline TA1 & $\begin{array}{l}1.00 \pm \\
0.26\end{array}$ & $\begin{array}{l}1.167 \pm \\
0.17\end{array}$ & $\begin{array}{l}1.00 \pm \\
0.25\end{array}$ & $\begin{array}{l}0.667 \pm \\
0.21^{*}\end{array}$ & $\begin{array}{l}0.833 \pm \\
0.17\end{array}$ & $\begin{array}{l}1.00 \pm \\
0.26\end{array}$ & $\begin{array}{l}0.667 \pm \\
0.21^{*}\end{array}$ & $\begin{array}{l}0.50 \pm \\
0.34^{*}\end{array}$ & $\begin{array}{l}1.50 \pm \\
0.34\end{array}$ & $\begin{array}{l}1.667 \pm \\
0.21\end{array}$ & $\begin{array}{l}2.00 \pm \\
0.26^{*}\end{array}$ \\
\hline TA2 & $\begin{array}{l}0.833 \pm \\
0.17\end{array}$ & $\begin{array}{l}1.00 \pm \\
0.26^{*}\end{array}$ & $\begin{array}{l}0.667 \pm \\
0.21^{*}\end{array}$ & $\begin{array}{l}0.50 \pm \\
0.22 * *\end{array}$ & $\begin{array}{l}0.667 \pm \\
0.33\end{array}$ & $\begin{array}{l}0.833 \pm \\
0.31\end{array}$ & $\begin{array}{l}0.50 \pm \\
0.22 *\end{array}$ & $\begin{array}{l}0.333 \pm \\
0.21 * *\end{array}$ & $\begin{array}{l}1.833 \pm \\
0.31 *\end{array}$ & $\begin{array}{l}2.00 \pm \\
0.37^{*}\end{array}$ & $\begin{array}{l}2.333 \pm \\
0.21^{* *}\end{array}$ \\
\hline TB1 & $\begin{array}{l}0.667 \pm \\
0.21\end{array}$ & $\begin{array}{l}0.833 \pm \\
0.17 * *\end{array}$ & $\begin{array}{l}0.333 \pm \\
0.21 * *\end{array}$ & $\begin{array}{l}0.333 \pm \\
0.21 * *\end{array}$ & $\begin{array}{l}0.333 \pm \\
0.21^{*}\end{array}$ & $\begin{array}{l}0.667 \pm \\
0.33^{*}\end{array}$ & $\begin{array}{l}0.333 \pm \\
0.21 * *\end{array}$ & $\begin{array}{l}0.167 \pm \\
0.17 * *\end{array}$ & $\begin{array}{l}2.00 \pm \\
0.26^{*}\end{array}$ & $\begin{array}{l}2.166 \pm \\
0.31 * *\end{array}$ & $\begin{array}{l}2.50 \pm \\
0.22 * *\end{array}$ \\
\hline
\end{tabular}

Values are expressed in Mean \pm SEM $(\mathrm{n}=6),{ }^{*} \mathrm{p}<0.05$, *** $<0.01$ vs Disease Control group, Data analyzed by One way ANNOVA test followed by Dunnet's multiple test for comparison. Treatment of various groups is as follows, DC: Disease Control, STD: Standard, TA1: WCME-200 mg/kg, TA2: WCME-500 mg/kg, TB1: WCHAE-4500 $\mathrm{mg} / \mathrm{kg}$

Figure 8:- Effect of WCE on Motility Score

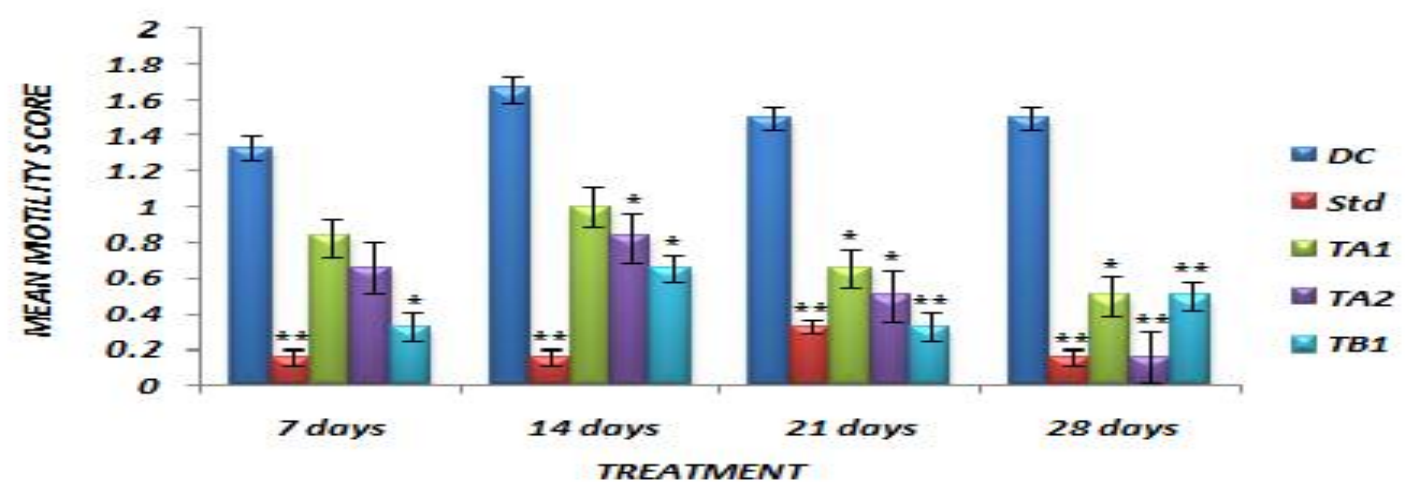

Values are expressed in mean \pm SEM $(\mathrm{n}=6),{ }^{*} \mathrm{p}<0.05$, ** $\mathrm{p}<0.01$ vs Disease Control group, Data analyzed by One way ANOVA test followed by Dunnet's multiple test for comparison. Treatment of various groups is as follows, DC: Disease Control, STD: Standard, TA1: WCME- $200 \mathrm{mg} / \mathrm{kg}$, TA2: WCME-500 mg/kg, TB1: WCHAE-450 $\mathrm{mg} / \mathrm{kg}$

\section{f) Effect of WCE on Stair Climb Score in FCA Induced Arthritis}

In present study it has been observed that FCA induced decreased motility score were significantly $(\mathrm{p}<0.05, \mathrm{p}<0.01$ and $\mathrm{p}<0.01)$ reduced by treatment with WCME-500, WCHAE-450 and indomethacin $(10 \mathrm{mg} / \mathrm{kg})$ on $28^{\text {th }}$ day in comparison with disease control group in FCA induced arthritis model respectively. As it has been observed in radiological study that ankle joint space of arthritic animals is retained effectively by continuous WCE treatment which may be responsible for enhanced motility behavior of arthritic animals which may lead to less stiffness in joints and more climbing capacity. 
Figure 9 :- Effect of WCE on Stair Climb Score

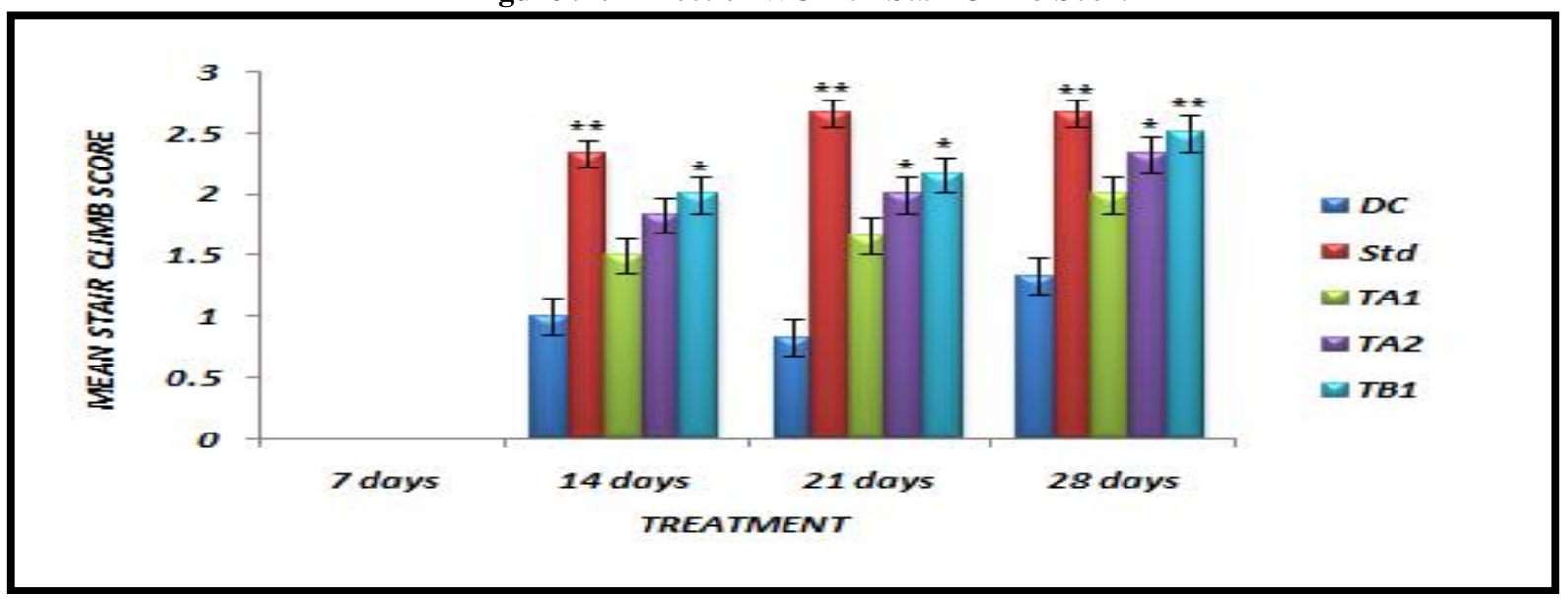

Values are expressed in mean \pm SEM $(\mathrm{n}=6),{ }^{*} \mathrm{p}<0.05, * * \mathrm{p}<0.01$ vs Disease Control group, Data analyzed by One way ANOVA test followed by Dunnet's multiple test for comparison. Treatment of various groups is as follows, DC: Disease Control, STD: Standard, TA1: WCME- 200 mg/kg, TA2: WCME-500 mg/kg, TB1: WCHAE-450 $\mathrm{mg} / \mathrm{kg}$

\section{g) Effect of WCE on Serum Transaminases in FCA Induced Arthritis}

In present study it has been observed that treatment of WCE significantly decreased the raised level of serum transaminases like SGOT, SGPT and ALP. On $28^{\text {th }}$ day WCME-200, WCME-500, WCHAE-450 and standard significantly $(\mathrm{p}<0.01, \mathrm{p}<0.01, \mathrm{p}<0.01$ and $\mathrm{p}<0.01)$ decrease the increased level of SGOT respectively. WCME-500, WCHAE-450 and standard significantly $(\mathrm{p}<0.05, \mathrm{p}<0.01$ and $\mathrm{p}<0.01)$ decrease the elevated and standard significantly $(p<0.05, p<0.01$ and $p<0.01)$ decrease the elevated level of SGPT respectively. WCME-200, WCME500 , WCHAE-450 and standard significantly $(p<0.01, p<0.01, p<0.01$ and $p<0.01)$ decrease the increased level of ALP in comparison to disease control group in FCA induced arthritis respectively.

Table 7:- Effect of WCE (200 mg/kg, 500mg/kg and $450 \mathrm{mg} / \mathrm{kg}$ ) on Serum Transaminases Level

\begin{tabular}{|c|c|c|c|}
\hline Experimental Group & SGOT (IU/L) & SGPT (IU/L) & ALP (IU/L) \\
\hline DC & $363.956 \pm 7.057$ & $182.706 \pm 8.068$ & $139.852 \pm 14.323$ \\
\hline N & $156.950 \pm 7.540^{* *}$ & $94.291 \pm 1.859^{* *}$ & $80.50 \pm 3.222^{* *}$ \\
\hline STD & $196.505 \pm 7.642^{* *}$ & $100.370 \pm 5.909^{* *}$ & $82.583 \pm 4.286^{* *}$ \\
\hline TA1 & $294.587 \pm 23.318^{* *}$ & $158.400 \pm 14.423$ & $110.966 \pm 4.295^{* *}$ \\
\hline TA2 & $251.066 \pm 10.357^{* *}$ & $146.766 \pm 10.075^{*}$ & $95.00 \pm 12.362^{* *}$ \\
\hline TB1 & $238.900 \pm 10.488^{* *}$ & $123.333 \pm 7.797^{* *}$ & $90.85 \pm 3.629^{* *}$ \\
\hline
\end{tabular}

Values are expressed in mean \pm SEM $(\mathrm{n}=6),{ }^{*} \mathrm{p}<0.05$, ** $\mathrm{p}<0.01$ vs Disease Control group, Data analyzed by One way ANOVA test followed by Dunnet's multiple test for comparison. Treatment of various groups is as follows, N: Normal, DC: Disease Control, STD: Standard, TA1: WCME- 200 mg/kg, TA2: WCME-500 mg/kg, TB1: WCHAE$450 \mathrm{mg} / \mathrm{kg}$ 
Figure 10:- Effect of WCE on Serum Transaminases

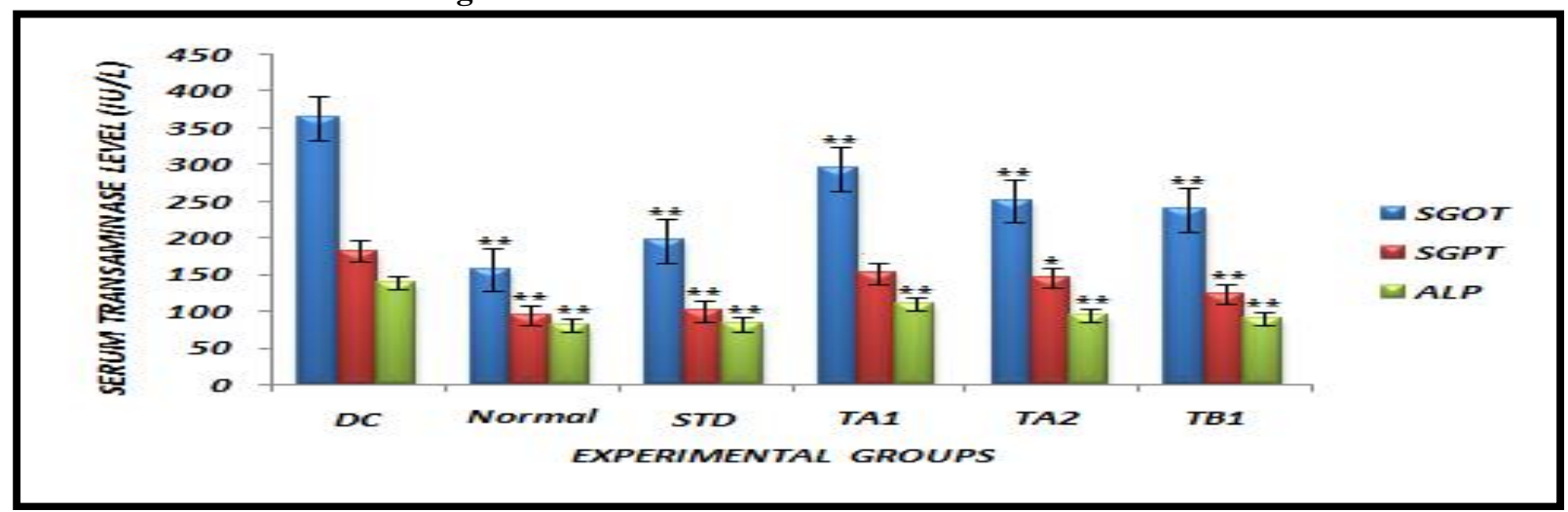

Values are expressed in mean \pm SEM $(n=6),{ }^{*}<<0.05$, **p<0.01 vs Disease Control group, Data analyzed by One way ANOVA test followed by Dunnet's multiple test for comparison. Treatment of various groups is as follows, Normal, DC: Disease Control, STD: Standard, TA1: WCME- 200 mg/kg, TA2: WCME-500 mg/kg, TB1: WCHAE$450 \mathrm{mg} / \mathrm{kg}$

\section{h) Effect of WCE on Hematological Parameters in FCA Induced Arthritis}

In present study it has been observed that treatment of WCME-200, WCME-500, WCHAE-450 and standard significantly $(\mathrm{p}<0.05, \mathrm{p}<0.05, \mathrm{p}<0.01$ and $\mathrm{p}<0.01)$ decreased the raised level of WBC(White Blood Cells) count. WCME-200, WCME-500, WCHAE-450 and standard significantly $(\mathrm{p}<0.05, \mathrm{p}<0.01, \mathrm{p}<0.01$ and $\mathrm{p}<0.01)$ decreased the raised level of ESR (Erytrocyte Sedimentation Rate).WCME-500, WCHAE-450 and standard significantly $(\mathrm{p}<0.05, \mathrm{p}<0.01)$ decreased the raised level of Platelets(PLT). WCME-200, WCME-500, WCHAE-450 and standard significantly $(\mathrm{p}<0.05, \mathrm{p}<0.01, \mathrm{p}<0.01$ and $\mathrm{p}<0.01)$ decreased the raised level Neutrophil (NEU) and Lymphocyte(LYM) to normal level. Whereas treatment of WCME-200, WCME-500, WCHAE-450 and standard significantly $(\mathrm{p}<0.05, \mathrm{p}<0.05, \mathrm{p}<0.01$ and $\mathrm{p}<0.01)$ increased the decreased level of RBC (Red Blood Cells) and HB (Hemoglobin) respectively. Treatment of WCME-500, WCHAE-450 and standard significantly $(\mathrm{p}<0.05, \mathrm{p}<0.05$, $\mathrm{p}<0.01)$ increased the decreased level HCT in comparison to disease control group in FCA induced arthritis.

Table 7:- Effect of WCE (200 mg/kg, 500mg/kg and $450 \mathrm{mg} / \mathrm{kg})$ on Hematological Parameters

\begin{tabular}{|c|c|c|c|c|c|c|c|c|}
\hline \multirow[b]{2}{*}{$\begin{array}{l}\text { Exp. } \\
\text { Grp }\end{array}$} & \multicolumn{8}{|c|}{ Hematological Parameters } \\
\hline & $\begin{array}{c}\text { WBC } \\
\text { (thousand/ } \\
\text { cu.mm) }\end{array}$ & $\begin{array}{c}\text { RBC } \\
\text { (million/ } \\
\text { cu.mm) }\end{array}$ & $\begin{array}{c}\text { HB } \\
(\mathrm{gm} / \mathrm{dl})\end{array}$ & $\begin{array}{c}\text { HCT } \\
(\%)\end{array}$ & $\begin{array}{c}\text { ESR } \\
(\mathrm{mm} / \mathrm{hr})\end{array}$ & $\begin{array}{c}\text { PLT } \\
\text { (Lakhs/ } \\
\text { ml) }\end{array}$ & $\begin{array}{c}\text { NEU } \\
(\%)\end{array}$ & $\begin{array}{c}\text { LYM } \\
(\%)\end{array}$ \\
\hline DC & $\begin{array}{c}19.283 \pm \\
1.542\end{array}$ & $\begin{array}{l}3.88 \pm \\
0.254\end{array}$ & $\begin{array}{c}6.166 \pm \\
0.619\end{array}$ & $\begin{array}{c}24.333 \pm \\
2.722\end{array}$ & $\begin{array}{c}9.833 \pm \\
1.352\end{array}$ & $\begin{array}{c}3.205 \pm \\
0.057\end{array}$ & $\begin{array}{c}43.76 \pm \\
2.216\end{array}$ & $\begin{array}{c}93.55 \pm \\
4.542\end{array}$ \\
\hline $\mathbf{N}$ & $\begin{array}{l}10.866 \pm \\
1.263 * *\end{array}$ & $\begin{array}{c}7.945 \pm \\
1.207 * *\end{array}$ & $\begin{array}{c}14.55 \pm \\
2.187 * *\end{array}$ & $\begin{array}{l}48.65 \pm \\
4.29 * *\end{array}$ & $\begin{array}{c}3.50 \pm \\
0.56^{* *}\end{array}$ & $\begin{array}{l}2.233 \pm \\
0.10 * *\end{array}$ & $\begin{array}{c}19.37 \pm \\
1.057 * *\end{array}$ & $\begin{array}{c}73.95 \pm \\
5.404 * *\end{array}$ \\
\hline STD & $\begin{array}{c}11.48 \pm \\
1.412 * *\end{array}$ & $\begin{array}{c}7.18 \pm \\
6.193 * *\end{array}$ & $\begin{array}{c}12.82 \pm \\
0.493 * *\end{array}$ & $\begin{array}{l}44.52 \pm \\
4.93 * *\end{array}$ & $\begin{array}{c}3.33 \pm \\
0.49 * *\end{array}$ & $\begin{array}{c}2.395 \pm \\
0.103 * *\end{array}$ & $\begin{array}{c}23.41 \pm \\
2.141 * *\end{array}$ & $\begin{array}{c}74.70 \pm \\
3.266 * *\end{array}$ \\
\hline TA1 & $\begin{array}{l}14.11 \pm \\
1.603 *\end{array}$ & $\begin{array}{l}6.193 \pm \\
0.302 *\end{array}$ & $\begin{array}{c}11.246 \pm \\
0.821 *\end{array}$ & $\begin{array}{c}36.33 \pm \\
2.502\end{array}$ & $\begin{array}{c}5.50 \pm \\
4.333 *\end{array}$ & $\begin{array}{c}3.015 \pm \\
0.085\end{array}$ & $\begin{array}{l}35.51 \pm \\
1.547 *\end{array}$ & $\begin{array}{l}79.37 \pm \\
1.135^{*}\end{array}$ \\
\hline TA2 & $\begin{array}{c}13.633 \pm \\
1.076 *\end{array}$ & $\begin{array}{l}6.425 \pm \\
0.719 *\end{array}$ & $\begin{array}{l}11.80 \pm \\
1.771 *\end{array}$ & $\begin{array}{l}38.05 \pm \\
3.831 *\end{array}$ & $\begin{array}{l}4.333 \pm \\
1.41 * *\end{array}$ & $\begin{array}{c}2.85 \pm \\
0.059 *\end{array}$ & $\begin{array}{l}30.145 \pm \\
1.893 * *\end{array}$ & $\begin{array}{c}77.22 \pm \\
2.390 * *\end{array}$ \\
\hline TB1 & $\begin{array}{l}12.633 \pm \\
1.171 * *\end{array}$ & $\begin{array}{c}6.811 \pm \\
0.254 * *\end{array}$ & $\begin{array}{l}12.366 \pm \\
0.931 * *\end{array}$ & $\begin{array}{l}40.55 \pm \\
2.440 *\end{array}$ & $\begin{array}{l}4.333 \pm \\
1.17 * *\end{array}$ & $\begin{array}{l}2.756 \pm \\
0.05 * *\end{array}$ & $\begin{array}{l}26.168 \pm \\
1.319 * *\end{array}$ & $\begin{array}{l}76.383 \pm \\
1.520 * *\end{array}$ \\
\hline
\end{tabular}

Values are expressed in mean \pm SEM $(n=6), *_{p}<0.05, * * p<0.01$ vs Disease Control group, Data analyzed by One way ANOVA test followed by Dunnet's multiple test for comparison. Treatment of various groups is as follows, N: Normal, DC: Disease Control, STD: Standard, TA1: WCME- 200 mg/kg, TA2: WCME-500 mg/kg, TB1: WCHAE-450 mg/kg 
Figure 11:- Effect of WCE on WBC, RBC, HB, HCT $\quad$ Figure 12:- Effect of WCE on ESR, Platelets
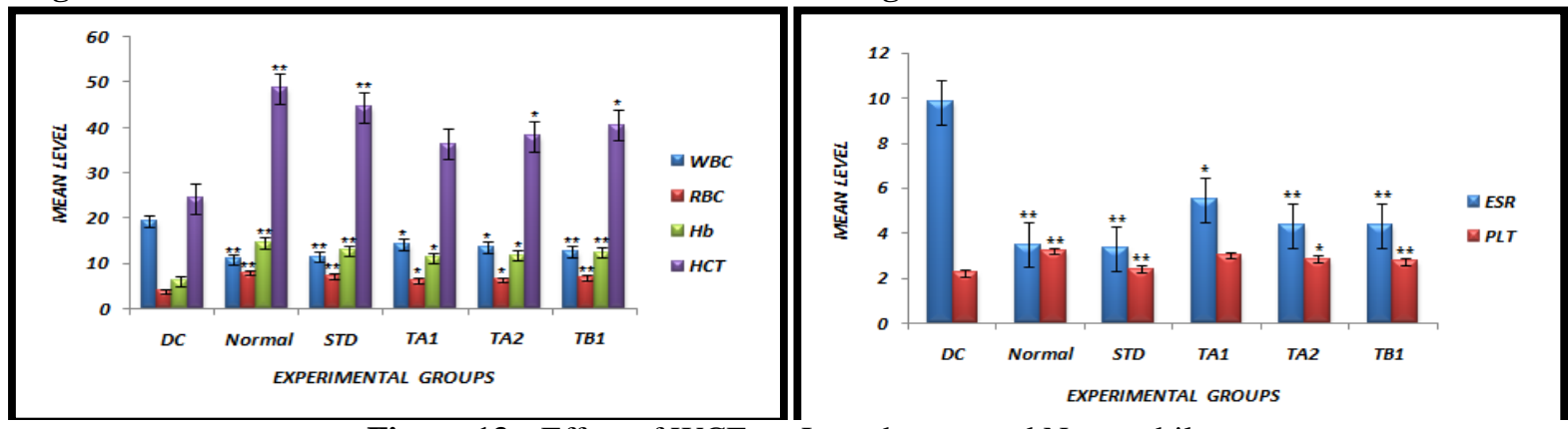

Figure 13:- Effect of WCE on Lymphocyte and Neutrophil

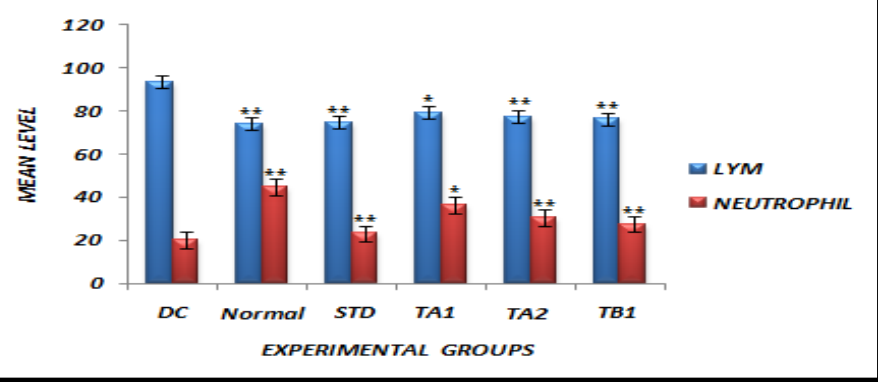

Values are expressed in mean \pm SEM $(n=6), * p<0.05$, **p<0.01 vs Disease Control group, Data analyzed by One way ANOVA test followed by Dunnet's multiple test for comparison. Treatment of various groups is as follows, N: Normal, DC: Disease Control, STD: Standard, TA1: WCME- 200 mg/kg, TA2: WCME-500 mg/kg, TB1: WCHAE$450 \mathrm{mg} / \mathrm{kg}$

\section{i) Effect of WCE on Different Organ Weight in FCA Induced Arthritis}

In case of liver arthritic rat shows increase in weight of liver whereas the Indomethacin and WCHAE-450 mg/kg shows significant $(\mathrm{p}<0.01$ and $\mathrm{p}<0.05)$ decreased the weight. In case of increased weight of kidney, Indomethacin and WCHAE-450 mg/kg shows significant $(\mathrm{p}<0.01$ and $\mathrm{p}<0.01)$ decrease in weight. In case of spleen Indomethacin, WCME-500 and WCHAE-450 mg/kg shows significant $(\mathrm{p}<0.01, \mathrm{p}<0.01$ and $\mathrm{p}<0.01)$ decrease in weight. Indomethacin, WCME-500 and WCHAE-450 mg/kg showed significant $(\mathrm{p}<0.01, \mathrm{p}<0.05$ and $\mathrm{p}<0.01)$ decrease in elevated weight of adrenal gland respectively. There were not significant changes observed in liver, kidney, spleen and adrenal gland weight in case of WCME-200 mg/kg.

Table 8:- Effect of WCE on Different Organ Weight in FCA Induced Arthritis

\begin{tabular}{|c|c|c|c|c|}
\hline \multirow{2}{*}{$\begin{array}{c}\text { Experimental } \\
\text { Group }\end{array}$} & Liver & Kidney & Spleen & Adrenal Gland \\
\cline { 2 - 5 } DC & $6.848 \pm$ & $0.70 \pm$ & $0.728 \pm$ & $0.065 \pm$ \\
& 0.4163 & 0.0318 & 0.0329 & 0.0086 \\
\hline N & $5.075 \pm$ & $0.396 \pm$ & $0.463 \pm$ & $0.0333 \pm$ \\
& $0.1018^{* *}$ & $0.0492^{* *}$ & $0.0449^{* *}$ & $0.0042^{* *}$ \\
\hline STD & $5.3183 \pm$ & $0.408 \pm$ & $0.4983 \pm$ & $0.0373 \pm$ \\
& $0.1742^{* *}$ & $0.0379^{*}$ & $0.6016^{* *}$ & $0.0034^{* *}$ \\
\hline TA1 & $6.318 \pm$ & $0.585 \pm$ & $0.6016 \pm$ & $0.050 \pm$ \\
& 0.2493 & 0.0592 & 0.0267 & 0.0025 \\
\hline TA2 & $6.102 \pm$ & $0.533 \pm$ & $0.5133 \pm$ & $0.0466 \pm$ \\
& 0.0675 & 0.0323 & $0.0575 * *$ & $0.0033^{*}$ \\
\hline TB1 & $5.613 \pm$ & $0.425 \pm$ & $0.5033 \pm$ & $0.0416 \pm$ \\
& $0.4464^{*}$ & $0.0802^{* *}$ & $0.0549 * *$ & $0.0047^{* *}$ \\
\hline
\end{tabular}

Values are expressed in mean \pm SEM $(n=6),{ }^{*}<0.05, * * p<0.01$ vs Disease Control group, Data analyzed by One way ANOVA test followed by Dunnet's multiple test for comparison. Treatment of various groups is as follows, N: Normal, DC: Disease Control, STD: Standard, TA1: WCME- 200 mg/kg, TA2: WCME-500 mg/kg, TB1: WCHAE$450 \mathrm{mg} / \mathrm{kg}$ 
Figure 14:- Effect of WCE on Liver Weight

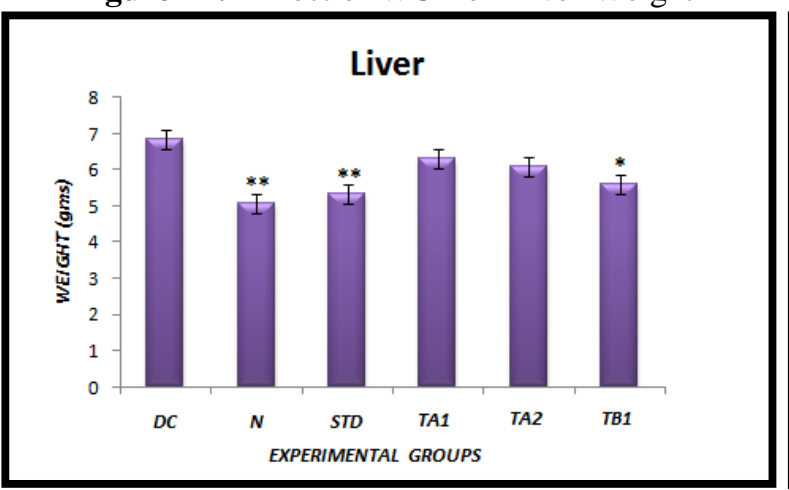

Figure 16:- Effect of WCE on Spleen Weight

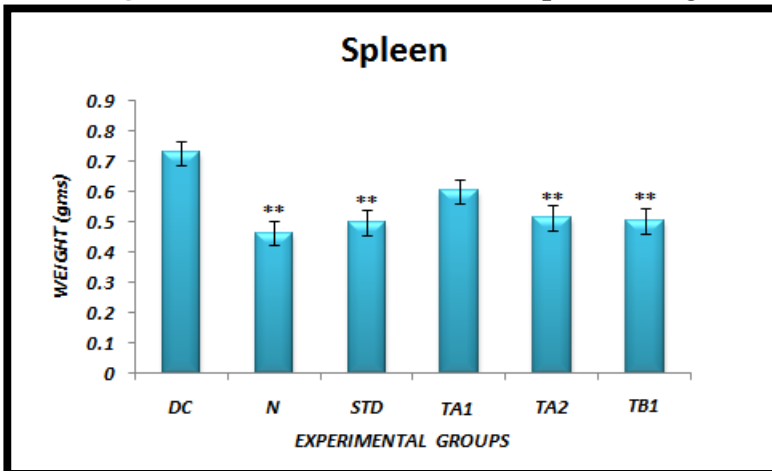

Figure 15:- Effect of WCE on Kidney Weight

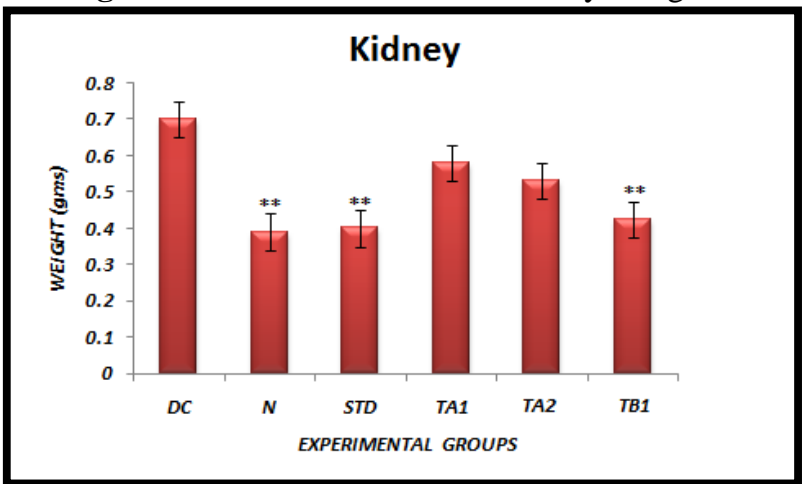

Figure 17:- Effect of WCE on Adrenal Gland Weight

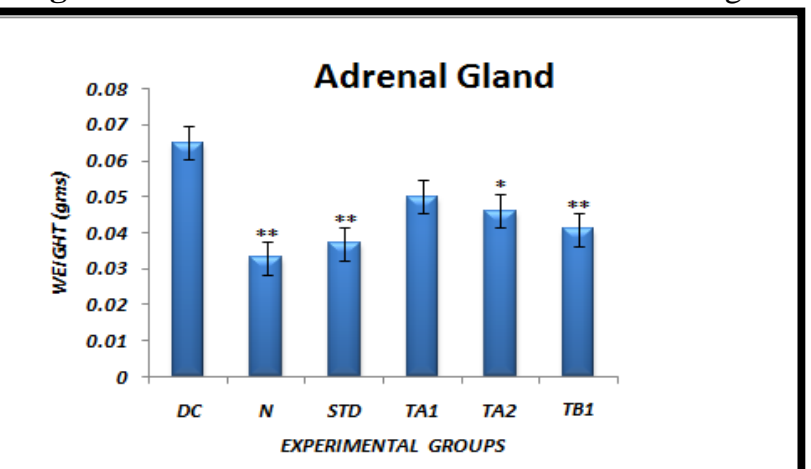

Treatment of various groups is as follows, N: Normal, DC: Disease Control, STD: Standard, TA1: WCME, TA2: WCHAE

\section{j) Effect of WCE on Body Weight in FCA Induced Arthritis}

In present study, it is clear from the data obtained that there is close relationship between the extent of joint inflammation and the degree of weight loss. In the first week after adjuvant injection, the arthritic rats showed marked weight loss, followed by normal weight gain in subsequent weeks whereas the WCME, WCHAE and standard drug treated groups did not show any weight loss. The significant $(\mathrm{p}<0.01)$ weight gain in the Indomethacin treated rats on $14^{\text {th }}$ and $28^{\text {th }}$ day. WCME-200 mg/kg treated group rats shows significant $(\mathrm{p}<0.05)$ weight gain on $28^{\text {th }}$ day whereas the WCME- $500 \mathrm{mg} / \mathrm{kg}$ and WCHAE- $450 \mathrm{mg} / \mathrm{kg}$ treated group rats shows significant $(\mathrm{p}<0.05$ and $\mathrm{p}<0.01$ ) weight gain on $14^{\text {th }}$ and $28^{\text {th }}$ day respectively.

Figure 18:- Effect of WCE on Body Weight

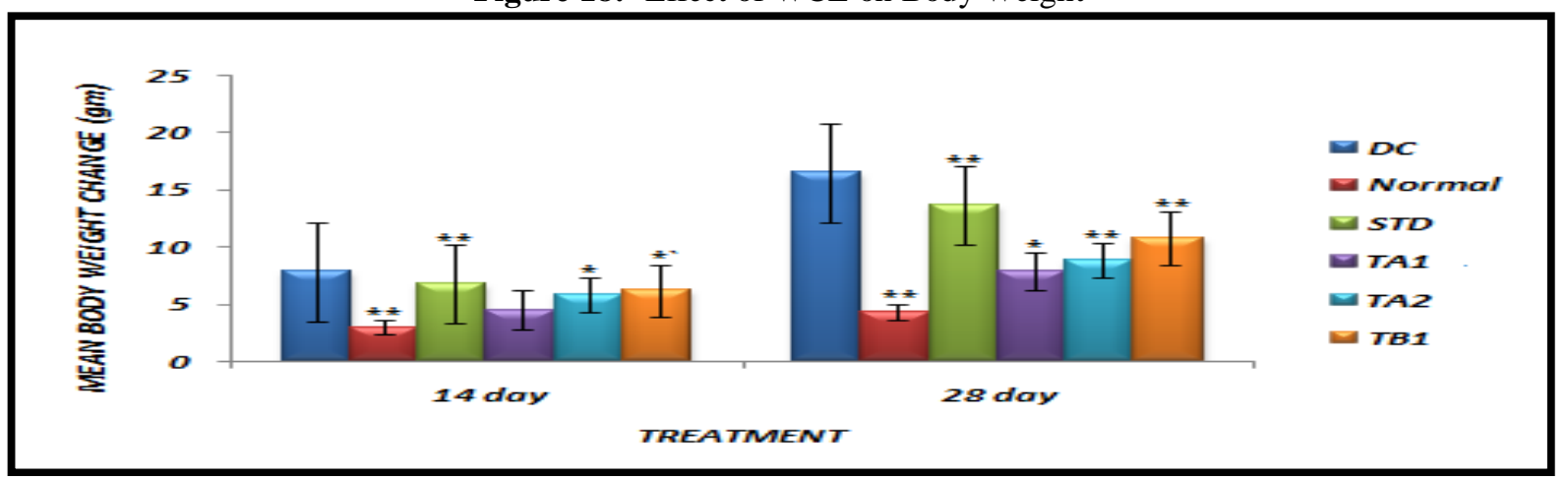

Values are expressed in mean \pm SEM $(n=6), * p<0.05, * * p<0.01$ vs Disease Control group, Data analyzed by One way ANOVA test followed by Dunnet's multiple test for comparison. Treatment of various groups is as follows, N: Normal, DC: Disease Control, STD: Standard, TA1: WCME- 200 mg/kg, TA2: WCME-500 mg/kg, TB1: WCHAE-450 mg/kg 
Table 9:- Effect of WCE on Body Weight in FCA Induced Arthritis

\begin{tabular}{|c|c|c|c|c|c|}
\hline \multirow{2}{*}{$\begin{array}{c}\text { Experimental } \\
\text { Group }\end{array}$} & \multicolumn{5}{|c|}{ Body Weight (gm) } \\
\cline { 2 - 6 } & 0 Day & $\mathbf{1 4}$ Day & $\mathbf{2 8 ~ D a y}$ & $\begin{array}{c}\text { Mean Changes } \\
\text { 0 Day - 28 Days }\end{array}$ & $\begin{array}{c}\text { Mean Changes } \\
\mathbf{1 4}^{\text {th }} \text { day-28 } \\
\text { dh } \\
\text { day }\end{array}$ \\
\hline DC & $184.33 \pm$ & $187.333 \pm$ & $190.33 \pm$ & $4.333 \pm$ & $3.00 \pm$ \\
& 3.190 & 3.630 & 4.104 & 0.667 & 0.5774 \\
\hline N & $185.5 \pm$ & $194.166 \pm$ & $202.0 \pm$ & $16.500 \pm$ & $7.833 \pm$ \\
& 3.106 & 2.845 & 2.921 & $0.7638^{* *}$ & $0.3073^{* *}$ \\
\hline STD & $183.0 \pm$ & $189.83 \pm$ & $196.66 \pm$ & $13.666 \pm$ & $6.833 \pm$ \\
& 3.337 & 3.833 & 3.694 & $0.8819^{* *}$ & $0.3073^{* *}$ \\
\hline TA1 & $183.16 \pm$ & $186.5 \pm$ & $191.0 \pm$ & $7.833 \pm$ & $4.50 \pm$ \\
& 3.114 & 3.128 & 2.933 & $0.6009^{*}$ & 0.6708 \\
\hline TA2 & $184.33 \pm$ & $187.33 \pm$ & $193.16 \pm$ & $8.833 \pm$ & $5.833 \pm$ \\
& 3.169 & 3.303 & 3.135 & $0.6009^{* *}$ & $0.6009^{*}$ \\
\hline TB1 & $182.83 \pm$ & $187.5 \pm$ & $193.66 \pm$ & $10.833 \pm$ & $6.166 \pm$ \\
& 3.027 & 2.895 & 2.486 & $1.558^{* *}$ & $1.400^{*}$ \\
\hline
\end{tabular}

Values are expressed in mean \pm SEM $(n=6),{ }^{*}<<0.05, * * p<0.01$ vs Disease Control group, Data analyzed by One way ANOVA test followed by Dunnet's multiple test for comparison. Treatment of various groups is as follows, N: Normal, DC: Disease Control, STD: Standard, TA1: WCME- 200 mg/kg, TA2: WCME-500 mg/kg, TB1: WCHAE$450 \mathrm{mg} / \mathrm{kg}$

\section{k) Radiographic Evaluation in FCA Induced Arthritis}

In present study on $14^{\text {th }}$ and $28^{\text {th }}$ day, radiological assessment of rat paw through X-rays showed significant reduction in various imaging parameters like spur formation, bone erosion, soft connective tissue swelling around ankle joint, calcium deposition and increase in interspacing between the bones in case of ankle joint, in Standard Indomethacin, WCME-200, WCME-500 and WCHAE-450 groups respectively in comparison with disease control group.

Figure 19:- Radiological Assessment of Arthritic Joint in Freund's Complete Adjuvant Arthritis

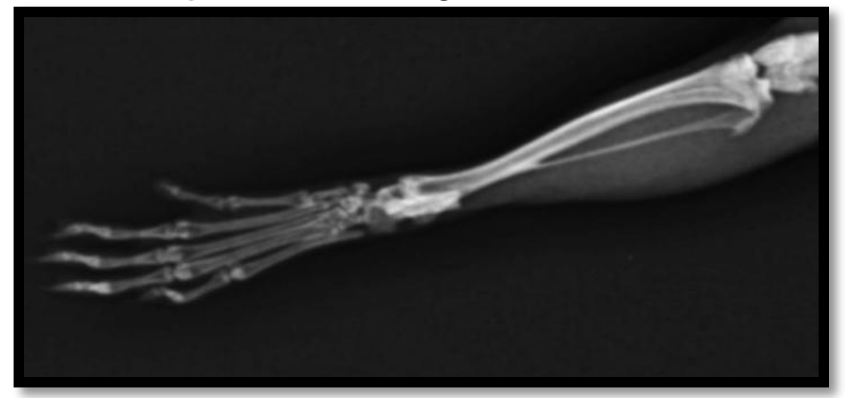

NC

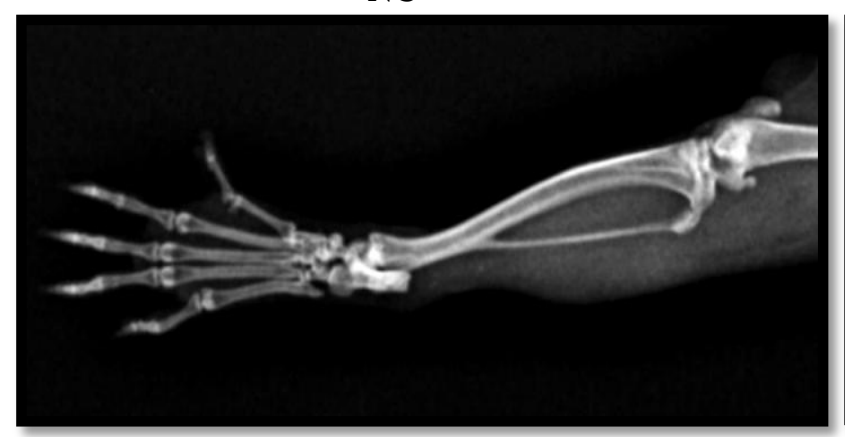

STD

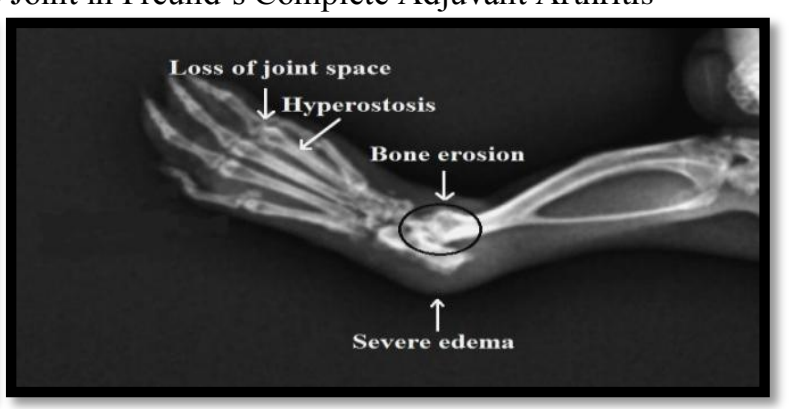

DC

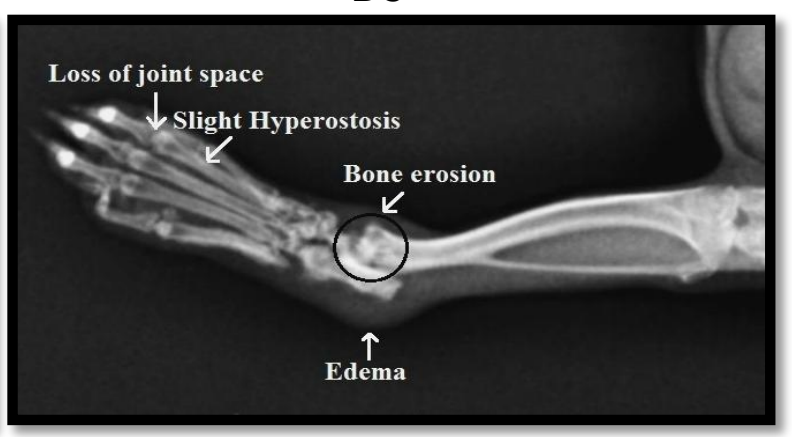

TA1 


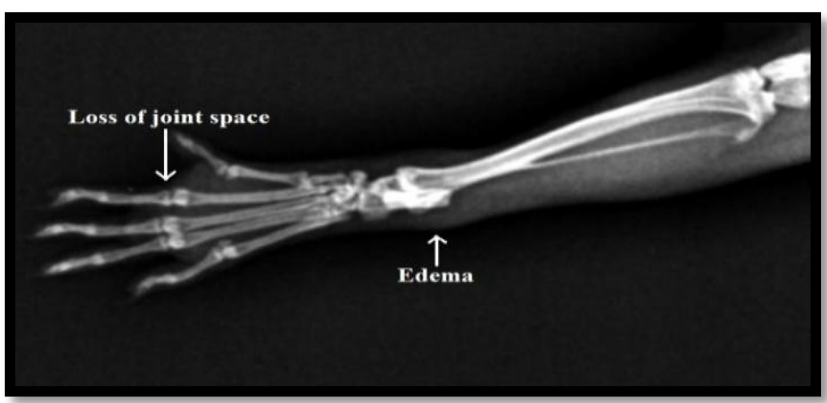

TA2

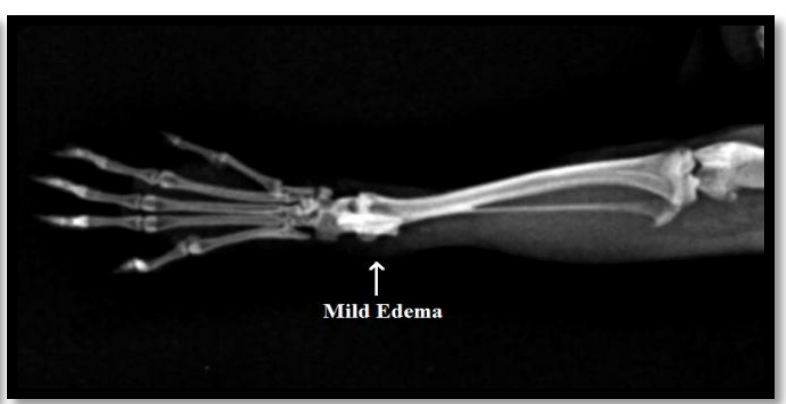

TB1

NC-Normal control, DC- Disease Control, STD- Standard, TA1- WCME-200 mg/kg, TA2-WCME-500 mg/kg, TB1-WCHAE-450 mg/kg

Table 10:- Effect of WCE on Radiographic Evaluation

\begin{tabular}{|c|c|c|}
\hline Groups & Dose & X-ray \\
\hline Normal & Distilled water & No soft tissue swelling with normal joint space \\
\hline Disease control & CFA $1 \% \mathrm{w} / \mathrm{v}$ & Soft tissue swelling with bone destruction \\
\hline Standard & $\begin{array}{c}\text { Indomethacin } \\
10 \mathrm{mg} / \mathrm{kg}\end{array}$ & Prevented bone destruction and soft tissue swelling \\
\hline TA1 & $200 \mathrm{mg} / \mathrm{kg}$ & Soft tissue swelling and bone destruction \\
\hline TA2 & $500 \mathrm{mg} / \mathrm{kg}$ & Less bone destruction and soft tissue swelling \\
\hline TB1 & $450 \mathrm{mg} / \mathrm{kg}$ & Prevented bone destruction and soft tissue swelling \\
\hline
\end{tabular}

Therefore from above study it was observed that both WCME and WCHA extract treatment shows significant antiarthritic activity.

\section{1) Histological Evaluation in FCA Induced Arthritis}

Histopathological studies of left hind paw joints in normal control rats shown intact articular cartilage and normal synovial lining. Distorted articular cartilage, bone erosion, synovial membrane lining cells hyperplasia, and infiltration of the inflammatory cells like lymphocytes and eosinophils were abundant in synovium and joint space in disease control rats. It was found that standard, WCME-500 mg/kg and WCHAE-450 mg/kg showed better retention of joint parameters like very less disruption of synovial cartilage, reduction in synovial hyperplasia, bone erosion, tissue infiltration with lymphocytes and eosinophils. While in case of treatment of WCME- $200 \mathrm{mg} / \mathrm{kg}$ group, above parameters were found to have slightly more effect in comparison with disease control group.

Figure 20:- Histological Assessment of Arthritis Joint in FCA Induced Arthritis

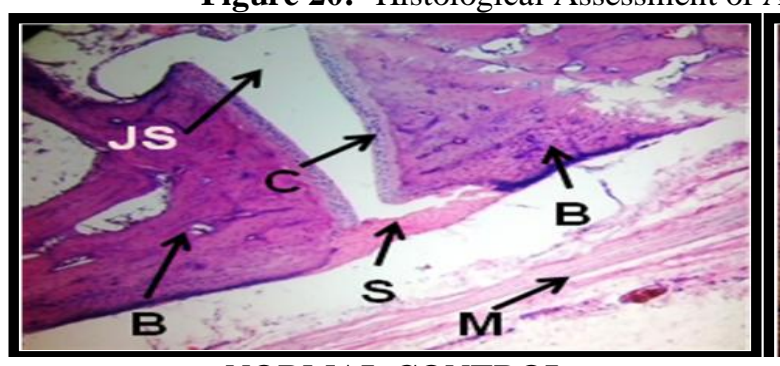

NORMAL CONTROL

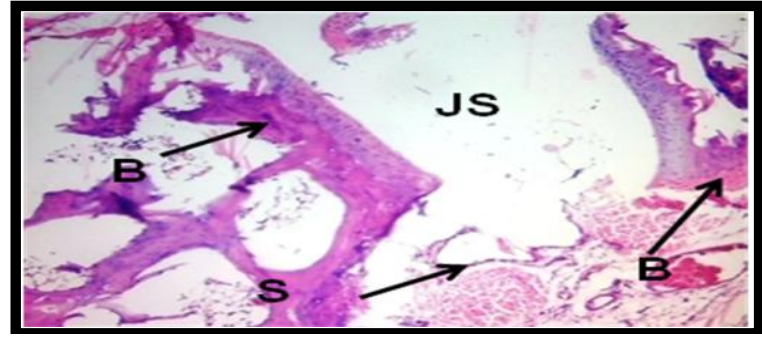

STANDARD

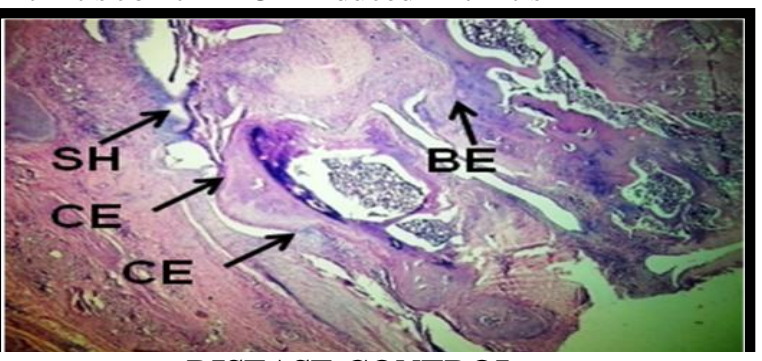

DISEASE CONTROL

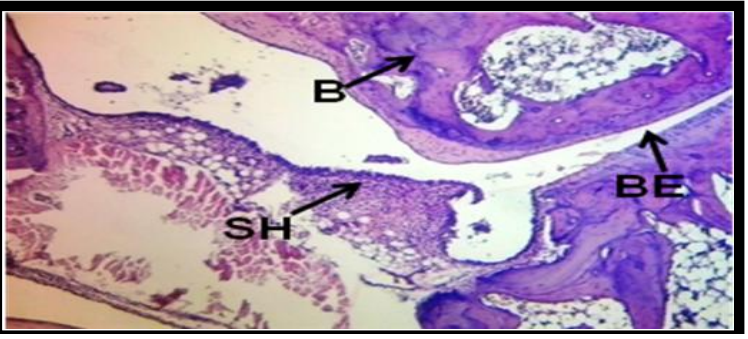

WCME-200 mg/kg 


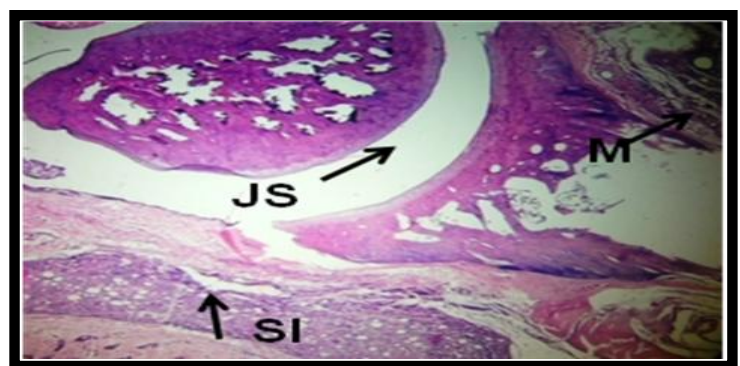

WCME-500 mg/kg

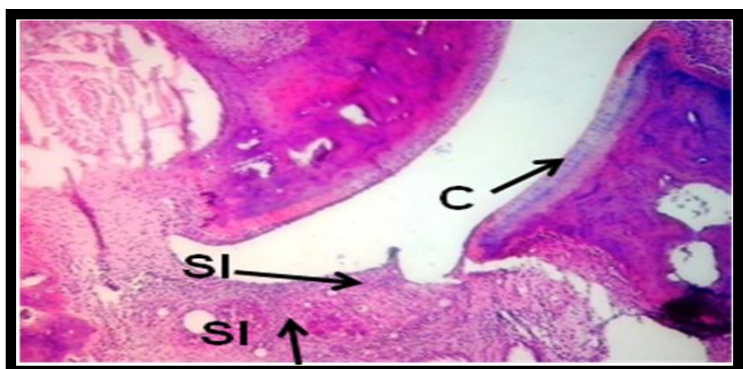

WCHAE-450 mg/kg

S: Synovium; B: Bone; C: Cartilage; JS: Joint Space; SH: Synovial Hyperplasia; SI: Synovial Infiltration of Inflammatory Cells; BE: Bone Erosion; CE: Cartilage Erosion; I: Infiltration.

Table 11:- Effect of WCE on Histology of Tibiotarsal Joint of Rats in FCA Induced Arthritis

\begin{tabular}{|c|c|c|}
\hline $\begin{array}{c}\text { Sr. } \\
\text { No. }\end{array}$ & Group & $\begin{array}{c}\text { Mean arthritis score } \\
\pm \text { S.E.M. }\end{array}$ \\
\hline $\mathbf{1}$ & N & 0 \\
\hline $\mathbf{2}$ & DC & $7.8 \pm 1.3$ \\
\hline $\mathbf{3}$ & STD & $0.83 \pm 0.5$ \\
\hline $\mathbf{4}$ & TA1 & $6.40 \pm 0.6$ \\
\hline $\mathbf{6}$ & TA2 & $5.50 \pm 0.4$ \\
\hline
\end{tabular}

Values are expressed as Mean \pm SEM where $\mathrm{n}=6$. NC-Normal control, DC: Disease Control, STD: Standard, TA1: WCME-200 mg/kg, TA2: WCME-500 mg/kg, TB1: WCHAE-450 mg/kg

Figure 21:- Effect of WCE on Histology of Tibiotarsal Joint of Rats

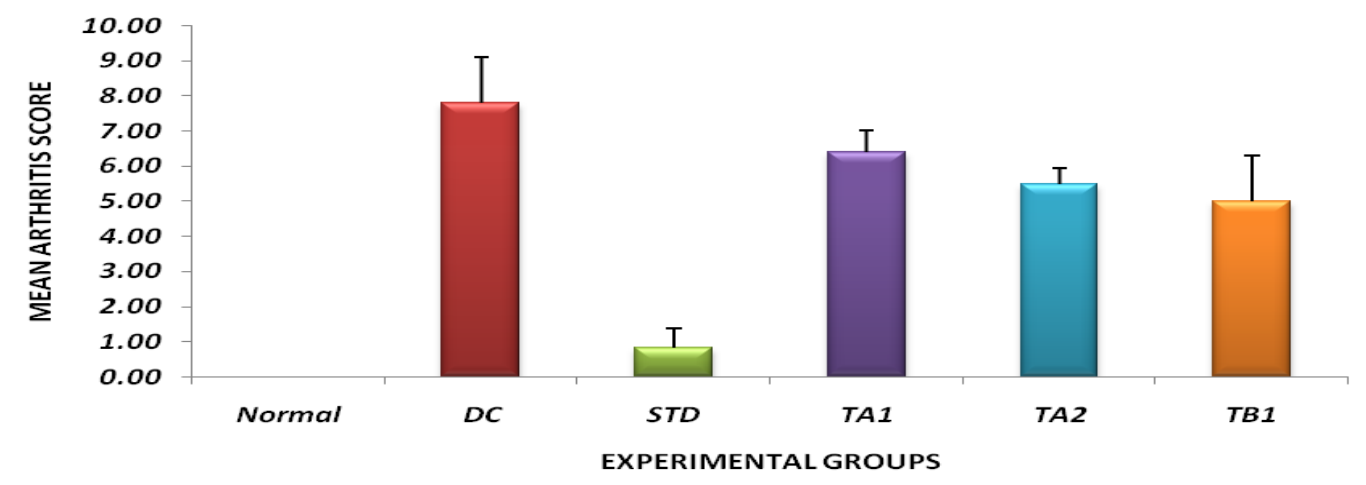

Values are expressed as Mean \pm SEM where $\mathrm{n}=6$. NC-Normal control, DC: Disease Control, STD: Standard, TA1: WCME-200 mg/kg, TA2: WCME-500 mg/kg, TB1: WCHAE-450 mg/kg

\section{Discussion:-}

In spite of discovery of several newer agents, the search for better anti-inflammatory drugs continues because of their existing side effects and none of them is suitable for prolonged used. These side effects of the antiinflammatory drugs are one of the major problems in developing medicine today. Therefore there need of development of new and more powerful drugs with fewer side effects. Therefore there is various alternatives like drug from herbal and animal origin were discovered with few side effects, herbal drugs like Vertex Negunda, Terminalia Arjuna ${ }^{[17]}$, Cassia Auriculata ${ }^{[18]}$ had shown effective anti- inflammatory activity in experimental animal models of inflammation and arthritic condition. In this research work we have primarily focused on the investigation of Withania Coagulans dunal fruits extracts against inflammatory and immune system conditions associated with RA. 
Rheumatoid arthritis is chronic, relapsing inflammatory and autoimmune multisystem illness that affects the joints. It is characterized by inflammation of the synovial membrane, pain and restricted joint movement, stiffness and swelling of joints. ${ }^{[19]}$ The process produce an inflammatory response of synovium (synovitis) secondary to hyperplasia of synovial cells, excess synovial fluid and the development of pannus in the synovium. The pathology of disease process often leads to the destruction of articular cartilage and ankylosis of the joints. In RA immune system activates the lymphocytes and chemical messenger like cytokine, TNF, IL-1 and IL-6 are expressed in inflamed area. This deregulation of the immune system may lead to the development of rheumatoid arthritis. Autoimmunity plays a pivotal role in both its chronicity and progression.

\section{In Vivo Anti-Arthritic Potential of WCE :-}

\section{Complete Freund's Adjuvant Induced Arthritis in Rats:-}

The evaluation of WCE for anti-arthritic potential was done with CFA model which has been used to induce an arthritic immunopathological condition that displayed many pathological features of human RA. ${ }^{[19]}$ Freund's adjuvant arthritis can be produced in rats by administration of Mycobacterium Tuberculosis suspended in oil in subplantar region of rat paw. Bacterial peptidoglycan and muramyl dipeptides are responsible for arthritic condition. It occurs through cell mediated autoimmunity by structural mimicry between mycobacteria and cartilage proteoglycan in rats. ${ }^{[20]}$ Liberation and overproduction of bradykinin, prostaglandin, and kinin in paw tissue. This model is also involves pannus formation, neutrophil infiltration and bone erosion. Arthritis typically persists during the first two week after its appearance. ${ }^{[21]}$ Severely affected animals eventually develop chronic deforming joint lesion.

In FCA induced arthritis it was observed that WCHAE than WCME significantly inhibited the arthritis index score, paw edema volume, joint area and pain perception parameters like dorsal flexion and motility along with rise in stair climb score in comparison with disease control for 28 days. After $14^{\text {th }}$ day in FCA prominent inhibition was observed in all parameters. The swelling has been found to be increasing in the initial phase of inflammation and then becomes constant in two weeks. The change in paw volume has been found to be associated with an increase in granulocyte and monocytes. Because, the activation of macrophages results in the production of several cytokines including IL-1, IL-6, interferon- $\gamma$ and TNF- $\alpha$ which have been implicated in immune arthritis.

Tissue damage was assessed by measuring the activity of enzyme in the serum. Liver impairment is also one of the features of adjuvant arthritis. The increase in the aminotransferase is due to their release from the cells of the damaged organ. Alkaline phosphtase activity has been reported to increase during the morphological and functional development of tissue. Thus ALP, SGOT, SGPT are good indices of liver and kidney impairment which is also considered as feature of adjuvant arthritis. To evaluate liver function, SGOT and SGPT levels were estimated. ${ }^{[22]}$ SGOT and SGPT has been reported to play a vital role in the formation of biologically active chemical mediators such as bradykinin in inflammatory process confirmed a positive correlation between the increased activity of serum alkaline phosphatase and disease activity of RA. ${ }^{[23]}$ Amino transferase and alkaline phosphtase were significantly reduced by WCHAE than WCME in arthritic rats. This reducing effect may be related to their anti-inflammatory and anti-arthritic effect. The decreased enzyme levels on WCME and WCHAE treatment emphasized decreased bone loss and organo protective role of WCME and WCHAE in CFA induced rats.

As the severity of arthritic condition increases level of inflammation rises in patient of RA. Along with rise in inflammation, level of WBC's also increases by virtue of autoimmunity. Hence the measurement of WBC's is an effective tool to assess the severity of disease state in RA patients. As a part of WBC's, B cells in patients with rheumatoid arthritis are usually secrets large amount of auto-antibodies which can enhance tissue destruction and release of auto-antigens, indicating that B-cells are also critically important in the severity and length of disease. ${ }^{\text {[24] }}$ The rise in WBC count is due to release of IL-1B increase the production of monocyte and colony stimulating factor. ${ }^{[25]}$

WBC count increase in arthritic rat to kill invading pathogenic microorganism. A large number of leucocytes that generate free radicals are present in the region of inflammation. Hence, free radical measurement reflects the number of leucocytes present in the inflammatory condition. ${ }^{[26]}$ It was observed that WCHAE than WCME significantly restored the increased WBC count to the normal in comparison to disease control group which may be possibly due to inhibition of matured bone marrow dendritic cell growth which might be responsible for innate immunity. This is probably due to inhibition of matured bone marrow dendritic cells, responsible for development of innate immunity and T-cell cytotoxicity by $\mathrm{PLA}_{2}$.The increase in WBC count is an indication of increased 
autoimmunity and level of inflammation along with anemic condition of animal due to decrease in RBC,HB and $\mathrm{HCT}$ as iron is deposited in connective tissue.

Anemia arises due to abnormal storage of iron in reticuloendothelial system and synovial tissue due to which RBC count, HB count and HCT value decreases below normal level. ${ }^{[27]}$ It was observed that RBC, $\mathrm{Hb}$ and Hematocrit values significantly increased in WCHAE than WCME, which might be due to the matured bone marrow cells respond to anemic condition by preventing abnormal deposition of iron in reticuloendothelial system and synovial tissue.

The increase in platelet count might be due to the stimulation of immune system against the invading pathogenic microorganism. This is evident by the infiltration of inflammatory mononuclear cells in the joint of arthritis rat. ${ }^{[28]}$ T-lymphocytes have been reported to play a central role in the pathogenesis of rheumatoid arthritis. These cells comprise the majority of the lymphoid cells found in the rheumatoid synovium. In arthritic condition there is a moderate elevation in lymphocyte count. In all treated groups the lymphocyte count was suppressed significantly as compared to control. ESR is an estimate of the suspension stability of RBC's in plasma, related to the number of size of red cells and to the relative concentration of plasma proteins especially fibrinogen and the $\alpha$ and $\beta$ globulins. The acute phase proteins in ESR share the property of showing elevations in the concentration in response to stress or inflammation that occurs like infection, injury, and surgery and tissue necrosis. So in arthritic condition, ESR is elevated. ${ }^{[13]}$ All the treated group significantly reduced the elevated level of ESR in comparison to disease control group.

In a chronic inflammatory process, such as RA, large numbers of neutrophils are attracted across the synovial membrane, and become activated. Neutrophils possess a range of potent proteinases and hydrolases, and have the ability to generate a series of reactive oxygen intermediates (ROI) via the combined activities of NADPH (reduced form) oxidase and myeloperoxidase (MPO). ${ }^{[29,30]}$ If the neutrophils are not efficiently depleted, their production of inflammatory mediators, such as ROI, could prolong the inflammatory reaction. In fact, inappropriate release of ROI from activated neutrophils is responsible for joint damage observed in RA. ${ }^{[31]}$ Beside ROI and inflammatory mediators, neutrophils are also an important source of proteolytic enzymes which play a role in degradation of articular structures. In present study all the treated group significantly reduced the elevated level of neutrophils in comparison to disease control group.

The changes in the body weight were monitored as apparent indicator of arthritic symptoms and the loss of body weight usually began to appear at the onset stage of arthritis. In the present study, the body weight decreased in arthritis induced animals might be linked to the systemic or local action of cytokines such as TNF- $\alpha$, since TNF- $\alpha$ has been closely related to the loss in body weight occurring in animals suffering from chronic inflammation. The loss of body weight observed in CFA induced arthritic rats may be due to the reduced absorption of ${ }^{14} \mathrm{C}$-glucose and ${ }^{14} \mathrm{C}$-leucine in the rat intestine. WCHAE than WCHAE showed significant increase in body weight reveals the restoration of absorption capacity of the intestine in the arthritic animals. ${ }^{[32]}$

In adjuvant treated rats an increase in lipid peroxide level was seen in liver and kidney. Liver and kidney weight were increased in AIA rats. WCHAE than WCME alter these values near to normal. Spleen is a vital organ serves as the reservoir for the cells and antibody formation which involved in the immune response. In adjuvant arthritis, spleen Increased in the weight of spleen is associated with the splenomegaly, generalized lymphadenopathy and altered hepatic function. In disease control group weight of spleen was significantly increased. ${ }^{[15]}$ In case of spleen and adrenal gland weight both of this result were significant in WCHAE than WCME treated rats.

Radiological changes in RA condition are useful diagnostic measure which indicates the severity of disease. Soft tissue swelling is the earlier radiographic sign, whereas the prominent radiographic changes like bone erosion narrowing of joints spaces can be observed only in the developed stages of arthritis. WCHAE than WCME groups $\mathrm{X}$ - rays showed significant reduction in various imaging parameters like hyperostosis, bone erosion, soft connective tissue swelling around ankle joint and increase in interspacing between the bones in case of ankle joint in comparison with disease control group.

In present study histological assessment of joint showed very less disruption of synovial cartilage, reduction in synovial hyperplasia, bone erosion, tissue infiltration with lymphocytes and eosinophils in case of WCME, WCHAE and standard treatment groups in comparison with disease control group in FCA induced arthritis. 
Thus, to summarize, WCME and WCHAE of fruits showed significant anti-arthritic and immunosuppressive activities probably by virtue of an underlying antioxidant activity.

\section{Conclusion:-}

- WCME oral treatment at both the doses- $250 \mathrm{mg} / \mathrm{kg}$ and $500 \mathrm{mg} / \mathrm{kg}$ demonstrated significant anti-arthritic activity.

- WCME-500 mg/kg provides more significant anti-arthritic activity and is comparable to the standard drug indomethacin.

- Whereas the WCHAE-450 mg/kg shows highly significant anti-arthritic activity and is comparable to the standard drug indomethacin.

Phytochemical constituents like flavonoides, alkaloids, saponin, glycosides, steroids and withanolides were already reported to anti-inflammatory, immunosuppressant and anti-arthritic activity and these constituents were present in both WCME and WCHAE. Hence these chemical constituents can be accounted for the observed anti-arthritis activity.

The present study aims to bring about value addition to the health benefits of Withania Coagulans dunal fruits establish it as a potent "functional food" and promote its use in people's diets. Besides, it is cheap, readily available to all strata of society, with medicinal properties attributed to it. Future research may be carried out to isolate the active constituents and bioactivity evaluation may be carried out.

\section{Acknowledgements:-}

The Authors are grateful to extend special thanks to Dr. Parrag Gide, Principal, and Dr.L.H.Hiranandani College of Pharmacy for his constant encouragement and support throughout the work.

\section{References:-}

1. Kumar K., Rai A.K., Evaluation of Anti-inflammatory and Anti-arthritic Activities of Floating Microspheres of Herbal Drug, Int Res J Pharmacy. 2012; 3(1):186-193.

2. Sudaroli M. and Chatterjee T.K., Evaluation of Red and White Seed Extracts of Abrus Precatorius Linn. Against Freund's Complete Adjuvant Induced Arthritis in Rats, J. Med. Plant. Res. 2007; 1(4):086-094.

3. Desai N.V., Patkar A.N., Shinde S.A., Pandav A.V., Prophylactic Effect of Aegle Marmelos Leaves Against Complete Freunds Adjuvant (CFA) Induced Arthritis, Asian Journal of Pharmaceutical Research and Development. 2013;1(1):96-104.

4. Ekambaram S., Perumal S.S., Subramanian V., Evaluation of anti-arthritic activity of Strychnos Potatorum Linn seeds in Freund's adjuvant induced arthritic rat model, BMC Complementary and Alternative Medicine. 2010; 10(56): $1-9$.

5. Babushetty V., Sultanpur C.M. Evaluation of Anti-Arthritis Activity of Asystasia Dalzelliana Leaves, International Journal of Pharmaceutical \& Biological Archives 2012; 3(2):377-382.

6. Prasad SK, Kumar R, Patel DK, and Hemalatha S. Wound healing activity of Withania Coagulans in Streptozotocin- Induced Diabetic Rats. Pharm Biol. 2010; 48(12):1397-1404.

7. Sangwan et al. Process for Isolation for Withaferin-A from Plant Material and Product Therefrom. U.S. Patent US 7,108,870, B2; 2006.

8. Khandelwal K.R. Practical Pharmacognosy Techniques and Experiments. Nirali Prakahan. 12th ed, 2008; pg no. 149 .

9. Castro Costa M.D., Sutter P., Gybels J. Adjuvant Induced Arthritis in Rats: A Possible Animal Model of Chronic Pain. Pain. 1981; 10(2):173-185.

10. Wang Y., Huang C., Cao Y., and Han J.S. Repeated Administration of Low Dose Ketamine for the Treatment of Monoarthritis in Rat. Life sciences. 2000; 67(3): 261-267.

11. Patil K.S., Suryavanshi, J. Effect of Celastrus Paniculata Willed Seed on Adjuvant Induced Arthritis In Rats. Pharmacognosy Magazine. 2007; 3(11): 177-181.

12. Newbould, B.B. Chemotherapy for Arthritis Induced in Rats by Mycobacterium Adjuvant, British Journal of Pharmacological Chemotherapeutic. 1963; 21:127-136.

13. Malik J.K., Manvi F.V., Nanjware B.R., Dwivedi D.K., Purohit P., Chouhan S. Anti-Arthritic Activity of Leaves of Gymnema Sylvestre R.Br. Leaves In Rats. Der Pharmacia Lettre. 2010; 2 (1): 336-341. 
14. Ritesh G. Patel, Nimish L. Pathak, Jaimik D. Rathod, Dr.Nurudin P. Jivani, Ravi U. Thaker, Nayna M Bhatt, Anti-Arthritic and Anti-Inflammatory Activity of Methanolic Extract of Randia Dumetorum Fruits In Freund's Complete Adjuvant Induced Arthritis. World J Pharm sci. 2012; 1(2): 309-325.

15. Mythilypriya R., Shanthi P., Sachdanandam P. Therapeutic Effect of Kalpaamruthaa, A Herbal Preparation on Adjuvant Induced Arthritis in Wistar Rats. Inflammopharmacology. 2008; 16(1):21-35.

16. Verma H., Shrivastava N. Changes in Certain Enzyme of The Ovary and Liver in Channa Punctatus. Electronic Journal of Ichthyology. 2010; 6:1-8.

17. Biswas M., Karan T.K., Bhattacharya S., Suresh Kumar R.B., Ghosh A.K., Haldar P.K. Pharmacologyonline. 2011; 1: 366-371.

18. Doshi G.M., Shahare M.D., Aggarwal G.V., Pillai P.G, Desai S.K. Anti-Inflammatory Potential of Cassia Auriculata Flowers. J Pharm Res Clin Practice. 2011; 1(2):50-58.

19. Billingham M.E. Models of Arthritis and The Search for Anti-Arthritic Drugs. Pharmacol Ther. 1983; 21(3):389-428.

20. Kabra M.P., Rachhadiya R.M., Shete R.V. Pharmacological Investigation of Hydroalcholic Extract of Ricinus Communis Leaves in Arthritis Induces Rats, AJBPR. 2011; 1(4):310-321.

21. Colapert F.C. Evidence that Adjuvant Arthritis in the Rat is Associated with Chronic Pain. Pain. 1987; 28: 201222.

22. Moura A.C.A, Silva E.L.F., Fraga M.C.A, Wanderley A.G., Afiatpour P., Maia M.B.S. Anti-inflammatory and Chronic Toxicity Study of the Leaves of Ageratum Conyzoides L. in Rats, Phytomedicine. 2005; 12(1-2): 138142.

23. Rajkapoor B. et al. Effect of Bauhinia Veriegata on Complete Freund's Adjuvant Induced Arthritis in Rats. J. Pharmacol. Toxicol. 2007; 2(5): 465-472.

24. Holmdahl R., Lorentzen J.C., Lu S., Olofsson P., Wester L., Holmberg J., Pettersson U. Arthritis Induced in Rats with Non-Immunogenic Adjuvants as Models for Rheumatoid Arthritis, Immunol Rev. 2001; 184:184-202.

25. Kumar K.E., Mastan S.K., Reddy K.R., Reddy G.A., Ragunandan N., Chitanya G. Anti- Arthritic Activity of Syzygium Cumini Seeds. IJIB. 2008; 4(1): 55-61.

26. Radharukmani.R., Krishnakumari.S., Makathi G. And Selvi V. Protective Effect of Rheumatocure-2004 on Various Hematological Parameters In CFA Induced Arthritic Rats. Ancient Science of Life. 2005; XXIV (4):15

27. Mowat G. Hematologic Abnormalities in Rheumatoid Arthritis. Semin Arthritis Rheum. 1972; 1: 195-219.

28. Bodhankar S.L., Kadam P. Anti-arthritic Activity of Ethanol Seed Extracts of Diplocyclos Palmatus (L) C. Jeffrey in Experimental Animals. Der Pharmacia Lettre. 2013; 5 (3):233-242.

29. Dularay B., Badesha J.S., Dieppe P.A., Elson C.J. Oxidative Response of Polymorphonuclear Leucocytes to Synovial Fluids from Patients with Rheumatoid Arthritis, Annals of the Rheumatic Diseases. 1990; 49:661-664.

30. Nurcombe H.L., Bucknall R.C., Edwards S.W. Neutrophils Isolated from the Synovial Fluid of Patients with Rheumatoid Arthritis: Priming and Activation In Vivo. Annals of the Rheumatic Diseases. 1991; 50:147-153.

31. Edwards S.W., Hallett M.B. Seeing the Wood for the Trees: The Forgotten Role of Neutrophils in Rheumatoid Arthritis. Immunology Today. 1997; 18(7): 320-324.

32. Somasundram S., Sadique J., Subramaniam. In Vitro Absorption of C Leucine During Inflammation and The Effect of Anti-Inflammatory Drugs in the Jejunum of Rats. Biochem Medica.1983; 29: 259-264. 